${ }^{2}$ Max-Planck-Institut für Meteorologie, Hamburg, Germany

\title{
The representation of a synoptic-scale weather system in a thermodynamically adjusted version of the ECHAM4 general circulation model
}

\author{
H.-S. Bauer ${ }^{1}$, V. Wulfmeyer ${ }^{1}$, L. Bengtsson ${ }^{2}$ \\ With 16 Figures
}

Received 19 July 2006; Accepted 7 August 2007

Published online 26 November 2007 C) Springer-Verlag 2007

\begin{abstract}
Summary
In this work, a strong cyclone event is simulated by the general circulation model (GCM) ECHAM4 for studying the representation of weather systems in a climate model. The system developed along the East Coast of the U.S.A. between the 12th and 14th of March 1993.

The GCM simulation was started from climatological conditions and was continuously forced to the analyzed state by a thermodynamical adjustment based on the Newtonian relaxation technique (nudging). Relaxation terms for vorticity, divergence, temperature, and the logarithm of surface pressure were added at each model level and time step. The necessary forcing files were calculated from the ECMWF re-analysis (ERA15). No nudging terms were added for the components of the water cycle.

Using this forcing, the model was able to reproduce the synoptic-scale features and its temporal development realistically after a spin-up period. This is true even for quantities that are not adjusted to the analysis (e.g., humidity). Detailed comparisons of the model simulations with available observations and the forcing ERA15 were performed for the cyclone case. Systematic errors were detected in the simulation of the thermodynamic state of the atmosphere, which can be traced back to deficiencies in model parametrizations. Differences in the representation of the surface fluxes lead
\end{abstract}

Correspondence: Hans-Stefan Bauer, Institute of Physics and Meteorology, University of Hohenheim, Garbenstraße 30, 70599 Stuttgart, Germany (E-mail: hsbauer@uni-hohenheim.de) to systematic deviations in near-surface temperature and wind fields. The general situation is very similar in both model representations. Errors were detected in the simulation of the convective boundary layer behind the cold front. The observed strong convective activity is missed both by the adjusted ECHAM4 simulation and ERA15. This is most likely caused by weaknesses in the cloud and convection schemes or by a too strong downdraft compensating the frontal lifting and suppressing the vertical transport of moisture from the boundary layer to higher levels. This work demonstrates for the investigated case the value of simulating single weather events in climate models for validating model physics.

\section{Introduction}

Usually, validation of GCMs is performed for long-term averages, for example by comparing monthly mean values of temperatures or $500 \mathrm{hPa}$ geopotential heights. These results have been applied for "tuning" of parameterization schemes in order to obtain a satisfactory large-scale response (Moncrieff 1995). This tuning and the temporal averaging hide model weaknesses occurring on shorter temporal and smaller spatial scales. Long integration periods are necessary to create such climatologies and corresponding 
observational data is only available for some of the interesting quantities. It is essential that GCMs are not only able to produce correct long-term averages but also the statistics of atmospheric variables due to weather events, particularly with respect to the simulation of regional water cycles. Only if the latter performance is acceptable, GCMs can be used as a guidance for decision making, e.g., for the change of water management due to climate change.

So far, in the majority of studies concerning the validation of ECHAM4, as for many other climate models, the climatological validation of long-term averages was preferred. Only a few studies dealt with the simulation of single weather events. One of the first who discussed the evolution of an Atlantic cyclone in a GCM was Gilchrist (1971). He used a five-layer model with a horizontal resolution of $5^{\circ}$ longitude and $3^{\circ}$ latitude, which covered the northern hemisphere. Despite the coarse resolution, many typical synoptic-scale features during the life-cycle were reproduced realistically. For the ECHAM model, first studies concentrating on the development of synoptic-scale systems were carried out by Bengtsson et al. (1995) and Chen and Roeckner (1997). The former investigated the representation of hurricane-type vortices in the ECHAM3 model and found a good representation of such systems in the evolving model climate. Chen and Roeckner (1997) validated the representation of clouds during the development of an average North Atlantic cyclone in ECHAM4. Their average cyclone was calculated from an ensemble of systems developed during one winter season.

In our work, the ability of ECHAM4 to reproduce a synoptic-scale weather system is investigated in more detail, using a low computational effort and permitting the validation of more quantities without the need of long-term averages. We study the temporal evolution of a distinct synoptic system using a high temporal and spatial resolution (from the point of view of climatological applications).

In order to simulate a single weather event that can be compared with synoptic data, it is essential that the model simulation is forced to the observed state. In numerical weather prediction (NWP), this is usually achieved by starting the simulation with a representation of the initial at- mospheric state, which should be as accurate as possible. This analysis is produced by a data assimilation system, which combines the information of an earlier model forecast with more recently measured observations of the atmospheric variables.

In our study we use a slightly different approach. The simulation was started from a climatological state and was continuously forced to the observed state using a four-dimensional data assimilation (FDDA) approach based on the "Newtonian relaxation technique" (nudging) (Krishnamurti et al. 1991; Jeuken et al. 1996). It forces the model thermodynamics to the observed state by adding a non-physical relaxation term to the model equations. Such a dynamical adjustment reduces the model spin-up characteristics compared to other data assimilation schemes, since it takes place at every time step rather than every few hours. This ensures a more gradual forcing of the model.

In our study, only the model thermodynamics is relaxed so that all components of the water cycle can develop freely. We evaluate how this relaxation process forces the model to the "real" thermodynamic state as prescribed by the ECMWF re-analysis (hereafter ERA15). To be able to separate errors caused by the initialization procedure from errors in the model representation of the dynamical and physical processes, we use ERA15 as a surrogate for the "true" atmospheric state. Differences between the reanalysis and the ECHAM4 simulation are then most likely caused by model differences. In addition, comparisons with observations are used to study whether remaining deviations in the thermodynamic fields are due to the nudging technique itself, or due to model initialization. It will be shown that our approach can indeed be used to detect deficiencies in boundary layer and convection parameterizations. Deviations in the representation of the components of the water cycle are discussed in more detail in a companion paper.

As synoptic system, the development of an extratropical cyclone along the East Coast of the U.S.A. between the 12th and 14th of March 1993 was chosen. This system was selected since it is one of the best documented cases of that kind in literature. Its development was predicted accurately by the models of the different fore- 
casting centers. The latter point was very important for the selection of the case since we use ERA15 as a surrogate for the "true" atmospheric state.

In addition, we mention results from a second synoptic situation that was investigated using this approach. Between the 15th and 23rd of February 1993 a blocking anticyclone developed over the central and eastern North Atlantic. For this situation we focus on relating the results to the findings for the cyclone development along the East Coast of the USA.

The following scientific questions are addressed:

- Can ECHAM4 be forced to the analyzed thermodynamical evolution of such systems?

- What systematic differences in thermodynamic fields occur during the evolution of the system?

- How far are these deviations due to the nudging technique, due to errors in initial fields, and due to model physics?

- What are the most important problems in the representation of model physics related to thermodynamical processes?

Recently, work to validate climate models in "numerical weather prediction mode" was performed by Phillips et al. (2004), Williamson et al. (2005) and Boyle et al. (2005). They forced the Community Atmospheric Model 2 (CAM2) with analyses of high resolution numerical weather prediction models, and compared the results with observations from the Southern Great Plains CART site to identify systematic deficiencies in the model representation. They found systematic differences between model results and ARM observations, and were able to relate them to the used physical parameterizations. In their approach they did not nudge the model to the analysis during the period of interest. This so-called numerical weather prediction (NWP) approach has the advantage, that the climate model's parameterizations are allowed to interact fully with the evolving model dynamics. Consequently, high-frequency feedback processes are presumably more realistically represented than in the continuously nudged approach, chosen in this paper. On the other hand, model errors increase more rapidly, and the model evolves into a completely different state within three days as compared to observation. As we were investigating the development of a weather system over sever- al days, we had to apply the continuous nudging approach.

In Sect. 2, a brief description of the main set-up of the model is given. Furthermore, the adjustment technique, its advantages and disadvantages, and the influence on the model thermodynamics are described. In Sect. 3, we investigate the representation of the selected system in the ECHAM4 model. First, a general introduction into East Coast Storms is given, before the synoptic development of the selected case is more closely investigated. The validation is divided into two parts. In this paper the representation of the thermodynamic state during the development of the system is investigated to assess the general usability of the proposed approach for validation purposes. The representation of the hydrological cycle in general, and clouds in particular, as well as sensitivity studies are investigated in a companion paper. In Sect. 4, we finish with a summary and some concluding remarks.

\section{Technical introduction}

\subsection{Model}

The model used in this study is the 4th generation of the Max Planck Institutes general circulation model ECHAM (ECMWF Model HAMburg version) (Roeckner et al. 1996). It is available at various horizontal resolutions from T21 to T106 triangular truncation. For this investigation the T106 horizontal resolution $(120 \times 120 \mathrm{~km}$ grid $)$ with 19 vertical hybrid levels up to a height of $30 \mathrm{~km}(10 \mathrm{hPa})$ was used. The time step was 12 minutes for the dynamics and physics and 2 hours for the radiation. ECHAM4 is based on the primitive equations and uses vorticity, divergence, temperature, the logarithm of surface pressure, water vapor, and cloud water as prognostic variables. In order to reduce truncation errors, the advection of water vapor, cloud water, and chemical substances is calculated using a semi-Lagrangian transport scheme (Williamson and Rasch 1989; 1994). The time integration is carried out using a semi-implicit "leap frog" method.

The radiation scheme is separated into two parts. The shortwave part, developed by Fouquart and Bonnel (1980), solves the radiative transfer 
equation by integrating the fluxes between 0.2 and $4 \mu \mathrm{m}$. During the integration, the visible part from 0.2 to $0.68 \mu \mathrm{m}$ and the near-infrared part from 0.68 to $4 \mu \mathrm{m}$ are treated differently. In the clear sky fractions the scheme accounts for scattering and absorption by molecules and aerosols. The single scattering properties of cloud droplets and ice crystals are calculated from Mie-theory with a suitable adaptation to a broad-band model (Rockel et al. 1991). The longwave part of the scheme is based on the one used in the ECMWF forecast model (Morcrette 1991). The water vapor continuum is modified following Giorgetta and Wild (1995), increasing the downward longwave radiation at the surface by $10-15 \mathrm{~W} / \mathrm{m}^{2}$ in agreement with observations.

The vertical turbulent transfer of momentum, heat, and mass is based on the Monin-Obukhov similarity theory for the surface layer and the eddy diffusivity approach in the layers above. The effect of orographically excited gravity waves is parametrized on the basis of a linear theory and dimensional considerations following Palmer et al. (1986) and Miller et al. (1989).

The cumulus convection is parametrized using the mass flux approach (Tiedtke 1989). The scheme includes the effects of deep, shallow, and mid-level convection in budget equations of heat, water vapor, and momentum. Following Nordeng (1994), the organized entrainment depends on local buoyancy while organized detrainment is calculated for a ensemble of clouds. The adjustment closure for deep convection relates cloud base mass flux to convective instability. The detrained fraction of the convectively generated cloud water is included as a source term in the stratiform cloud water equation.

The prediction of stratiform clouds and precipitation is based on the cloud water transport equation including sources and sinks due to condensation/evaporation, and precipitation formation by coalescense of cloud droplets and sedimentation of ice crystals (Sundqvist 1978; Roeckner et al. 1991). Sub-grid scale condensation and cloud formation is taken into account by specifying height-dependent thresholds of relative humidity (Xu and Kruger 1991; Walcek 1994). The same threshold is applied to both convective and stratiform clouds. The separation between liquid, ice, and mixed-phase clouds is done diagnostically according to ambient tem- perature (Matveev 1984; Roeckner et al. 1991). The effective radii of cloud droplets are parametrized as a function of the cloud water content. The effective radii of ice crystals are functions of the ice water content based on empirical data (Heymsfield 1977; McFarlane et al. 1992). The number concentration of cloud droplets are specified (100 and $220 \mathrm{~cm}^{-3}$ are assigned to the low-level maritime and continental clouds, respectively, and these numbers are gradually reduced to $50 \mathrm{~cm}^{-3}$ in upper layers).

\subsection{The thermodynamical adjustment}

In climate simulations, the necessary prognostic variables are usually initialized with climatological values assuming that the long-term averages of the meteorological variables are predicted correctly. In contrast, in NWP, the evolution of the atmosphere over time scales of days shall be predicted as accurate as possible. Therefore, it is necessary to provide the model with an accurate initial state. For this purpose, a data assimilation scheme is required, which derives this initial state, the so-called analysis, as the best compromise between an earlier model forecast and available observations.

To be able to study the performance of a climate model with respect to the representation of weather processes, it is necessary to force the model to the observed state. This can be achieved by providing the model with an accurate representation of the initial state at the beginning of the development of the situation of interest. However, this procedure does hardly allow to relate errors in the model forecast to errors in the initial state or in parameterizations since a climate model, primarily not specialized to predict weather, diverges much faster from the observed track than a numerical weather prediction model (Boyle et al. 2005). Alternatively, the model can be initialized from a climatological state and forced to the atmospheric state over a "spinup" period before the synoptic systems of interest develop. If it is possible to show that the models develops the correct thermodynamic state and if this forcing is continued during the whole weather period of interest, it can be investigated whether remaining systematic errors are due to inadequate parameterization. This is the goal of this study. 
Here, ECHAM4 is continuously forced to the observed state using a four-dimensional data assimilation (FDDA) scheme based on the "Newtonian relaxation technique" or "nudging" (Krishnamurti et al. 1991; Jeuken et al. 1996). FDDA was originally developed to include asynoptic data like satellite or aircraft measurements into numerical weather prediction systems. Hoke and Anthes (1976) used this approach almost 30 years ago for the improvement of hurricane forecast models. Krishnamurti et al. (1991; 1993) used satellite observations of precipitation from the Special Sensor Microwave/Imager (SSM/I) to improve the initial state for forecasts with a high-resolution global spectral model. They found a large improvement of the overall tropical forecast and a much better prediction of even mesoscale tropical features as the internal structure of tropical cyclones (Krishnamurti et al. 1993).

Today, FDDA is also widely used in operational numerical weather prediction (NWP) because of its easy implementation and low computational demands. Stauffer and Seaman $(1990 ; 1994)$ implemented the FDDA scheme into the mesoscale NWP model MM5 (Grell et al. 1995), where nudging is possible with gridded analysis as well as with observations distributed unevenly in space and time. For the same reasons the observation nudging is used in the mesoscale NWP model LokalModell (Doms et al. 2001; 2005) of the German Weather service (DWD).

However, the method has some drawbacks. It contains no mathematical formalism to determine the theoretically optimal solution of the analysis problem. Therefore, several free parameters exist that have to be adjusted in tuning experiments. Correlations of observation and model errors are not explicitly used for the assimilation. Instead, a non-physical forcing term is added to the model prognostic variables containing a timescale during which the adjustment to the observed state occur. In recent years, much work was spent on the development of more sophisticated assimilation schemes as the variational method (3DVAR and especially 4DVAR), which includes the influence of observation and model errors in covariance matrices to determine the spatial and temporal influence of observations in the model domain. Another disadvantage in comparison to the variational approach is, that the observation increments has to be described in model space rather than in observational space. For each observing system it is necessary to deduce increments of the model prognostic variables temperature, humidity and/or wind. This is only possible by using error prone additional assumptions. The drawbacks mentioned so far are, however, not a problem in our case, since we use re-analysis data for the assimilation, which directly provides the needed model variables, and we consider the re-analysis to represent the true atmospheric state.

The application of FDDA for the validation of physical parameterization schemes of GCMs is a relatively new idea. Hereby, the large scale components of the model circulation are adjusted towards meteorological analyse, whereas the small-scale processes, represented by the parameterization schemes, evolve freely (Jeuken et al. 1996). FDDA dynamically couples observed variables with the prognostic variables in the general circulation model by adding non-physical relaxation terms to the prognostic equations at each time step and model grid point.

$\frac{\partial X_{m}}{\partial t}=F_{m}\left(X_{m}\right)+G \cdot\left(X_{\mathrm{obs}}-X_{m}\right)$,

where $X_{m}$ is the model prognostic variable, $F_{m}$ is the model forcing and $G\left(X_{\mathrm{obs}}-X_{m}\right)$ is the relaxation term (or nudging term). The latter is expressed as the product of the relaxation coefficient $G$, and the difference between the observation and the value calculated by the model. $G$ determines the timescale during which the relaxation is carried out. In ECHAM4 this relaxation is performed in two steps. First, the model forcing $F_{m}$ is calculated yielding a new value for the prognostic variable. Afterwards, the new model value is calculated with the observation. Discretization of Eq. (1) into the "leap frog" scheme of the model leads to

$\frac{X_{\text {new }}-X_{\text {old }}}{2 \Delta t}=G(X)\left[X_{\text {obs }}-X_{\text {new }}\right]$,

where $X_{\text {new }}$ and $X_{\text {old }}$ are the values of the model prognostic variable at the new and the old model time step and $\Delta t$ is the model time step. Defining an adjustment weight $C(X)=2 \Delta t \cdot G(X)$ and solving the equation for the new model time step $X_{\text {new }}$ leads to the equation which is finally implemented into the model. The new model value is 
calculated as a linear combination of the old model value $X_{\text {old }}$ and the observation $X_{\text {obs }}$, both depending on the adjustment weight $\mathrm{C}(\mathrm{X})$.

$X_{\text {new }}=\left(\frac{1}{1+C(X)}\right) \cdot X_{\mathrm{old}}+\left(\frac{C(X)}{1+C(X)}\right) \cdot X_{\mathrm{obs}}$

Since observational data is neither available at every model time step (12 minutes) nor at every grid point on the globe, the ECHAM4 model is adjusted to ERA15, which provides data every six hours. For the interpolation to the time steps in between, a simple linear interpolation is used. According to Jeuken et al. (1996) and Kirchner (1999) a more sophisticated cubic spline interpolation did not lead to significant improvements of the results. Furthermore, a vertical interpolation from the 31 levels used in ERA15 to the 19 levels used in ECHAM4 was applied. One thing to keep in mind when forcing a general circulation model to the observed state is that it is usually driven by monthly mean sea surface temperatures. Therefore, it is hardly possible to exactly reproduce the observed surface conditions over the ocean.

Each change of the model calculated value results in inconsistencies with the model dynamics and physical parameterizations due to the included increments. These imbalances are dissipated as gravity waves after some time (hours to days). However, in the meantime the model contains noise which can significantly disturb the three-dimensional divergence and associated fluxes (Kållberg 1997). Although model spin-up cannot be avoided completely, the used dynamical adjustment has advantages compared to other data assimilation schemes (e.g., 3DVAR). Since the relaxation is carried out at every model time step, this more gradual adjustment to the observed state reduces largely the production of noise, and maintains the full dynamical and physical interactions of the model to generate its own, internally consistent, evolution of the physical processes.

One main issue when using FDDA is the choice of variables to be adjusted. A speciality of this study was that only thermodynamic variables were nudged. For this investigation the approach of Jeuken et al. (1996) was used and vorticity, divergence, and temperature at each model level, and the logarithm of surface pressure were adjusted. No variables related to water were nudged in order to study whether a climatological initialization of water in all its phases was sufficient to force the model to develop correct water vapor, cloud, and precipitation fields. Bengtsson and Hodges (2005) investigated the impact of humidity observations in numerical weather prediction and concluded that, at least in large-scale applications, the impact of humidity observations on the forecasts is small. Due to the large spatial and temporal variability of the moisture field an accurate initialization is furthermore not possible without high-resolution observations. However, it is expected that for higher resolution applications an additional consideration of the high-resolution moisture distribution is necessary to force the model to the observed state. Errico et al. (2004) concluded from experiments with a regional mesoscale model, that as much attention must be paid to moisture analysis as to analysis of other fields, and that ensemble forecast techniques should consider the initial moisture uncertainty.

The other issue is the choice of appropriate relaxation coefficients $G$. A too large relaxation term would dominate the model forcing, and would therefore suppress characteristic features (and errors) of the model. Furthermore, errors in the reanalysis can be spuriously amplified. A too small relaxation term would not force the model to the observed state, so that a validation with observational data would not be meaningful. In this study, we set the relaxation coefficients to the values given in Table 1, which are suggested by Jeuken et al. (1996). Different nudging coefficients for the different variables were required to account for the different correlation length scales of the variables.

Figure 1 shows the temporal set-up of the model simulation. It was started on the 1 st of January 1993 from climatological conditions. A spin-up of nearly $2 \frac{1}{2}$ month ensured that the adjustment tendencies were small when the inte-

Table 1. Adjusted variables and their used relaxation coefficients $G$

\begin{tabular}{ll}
\hline Nudged variable & $\mathbf{G}\left[\mathbf{s}^{-\mathbf{1}}\right]$ \\
\hline Vorticity & $1.0 \times 10^{-4}$ \\
Divergence & $5.0 \times 10^{-5}$ \\
Temperature & $1.0 \times 10^{-5}$ \\
Surface pressure & $1.0 \times 10^{-4}$ \\
\hline
\end{tabular}




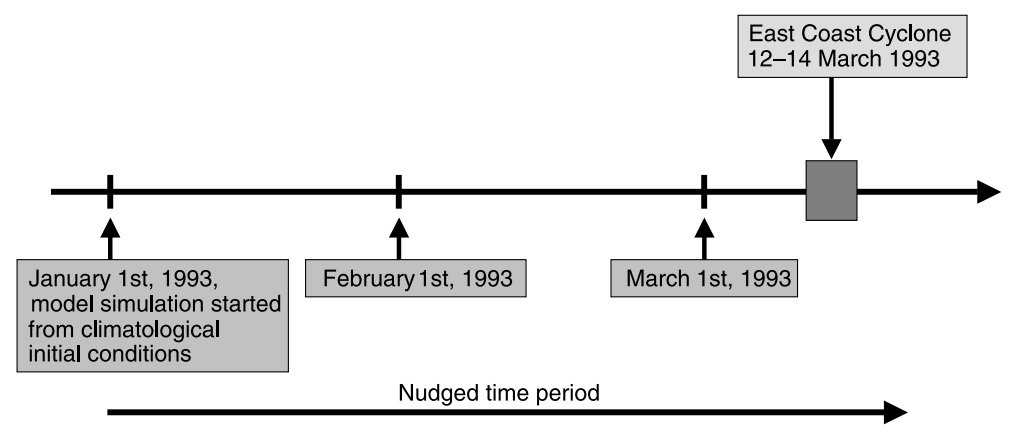

Fig. 1. Temporal setup of the model experiment. It was initialised from climatological values at the 1 st of January 1993 and continuously nudged to ERA15 data until the end of the simulation

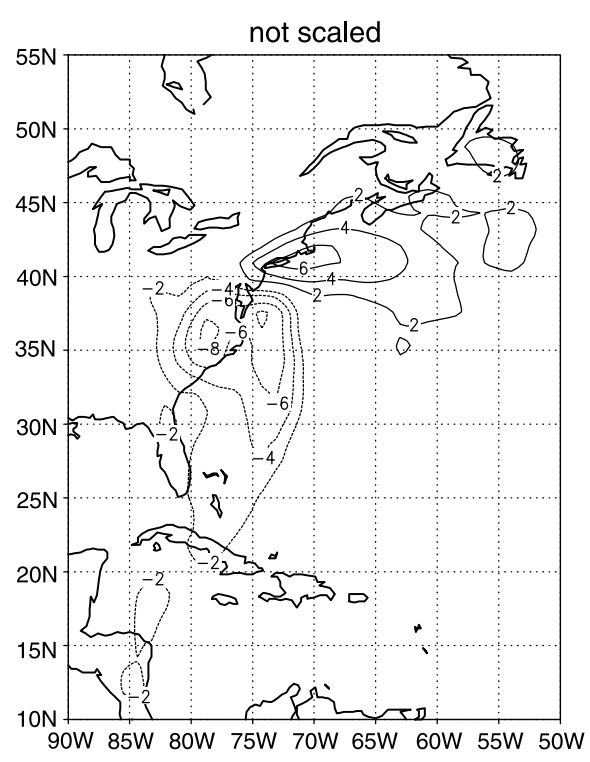

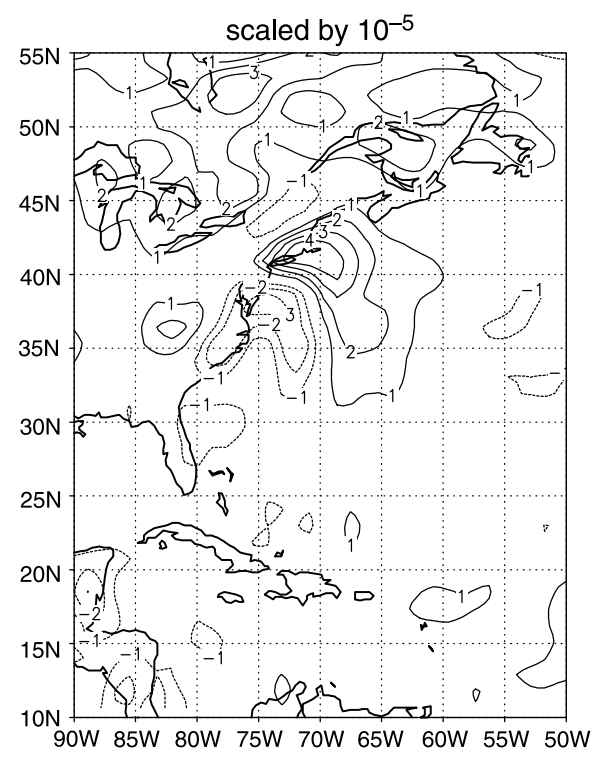

Fig. 2. Dynamical tendency (left) and adjustment tendency (right) of ECHAM4 for the temperature at model level 15 $(\sim 850 \mathrm{hPa})[\mathrm{K} / 3 \mathrm{~h}]$ (at $00 \mathrm{Z}$, 14th of March 1993). Note that the field on the right plot is scaled by $10^{-5}$ to use the same contour interval gration reached the period of interest for the selected case. The influence of the adjustment on the model balance is illustrated by the comparison of the dynamical tendency of the model and the tendency introduced only by the adjustment procedure. Figure 2 shows an example for temperature at $850 \mathrm{hPa}$ on 14 March 1993 at 00Z. It is clearly seen that the influence of the adjustment on the tendency of the variable is orders of magnitude smaller as compared to the dynamical tendency due to the developing synoptic system. The same was true for the other adjusted quantities (not shown).

To check how fast ECHAM4 would diverge from the observed track when the nudging is not used, a short forecast experiment was performed. We took the initial state on 00Z, 13th of March 1993, created during the nudging run, and started the ECHAM4 model without the ERA15 forcing. Then, the results were compared with the re-analysis. Since the initial condition was the result of a more than two month long nudging run, the model follows the re-analysis very well during the first 24 hours. However, after two days, the differences between ECHAM4 and ERA15 became clearly visible with a different state occurring afer 3 days.

The backbone of the following comparison is the ECMWF Re-Analysis (ERA15). In comparison to the operational analysis, it is not affected by changes in the model, analysis technique, assimilation system, and observation usage. ERA15 offers a validated 15-year data set for the period 1979-1993. The system used to produce the re-analysis contains a data assimilation system based on the optimal interpolation method, and the simulations were performed using T106 horizontal resolution (same as used for the adjusted ECHAM4 simulations), and 31 vertical levels.

Although ERA15 is a model product as ECHAM4, it can be expected to closely represent the observed state due to the use of a data assim- 
ilation procedure in which a large amount of observations is included. Though this is not always and everywhere the case, there is no other possibility in our methodology as to use the re-analysis as the most probable state of the atmosphere. While strong deviations from observations can still occur, nevertheless, with the assumption that the re-analysis represents a good approximation of the true atmospheric state, the developing differences between ERA15 and ECHAM4 can be traced back to differences in the used physical and numerical schemes. In addition, other available observations as satellite observations, or station data mentioned in the literature describing the developing East Coast Storm are used to judge the representation of the truth in the re-analysis.

\section{Results}

\subsection{East coast blizzard}

\subsubsection{General introduction}

Severe snow storms are a major concern along the East Coast of the US. Such storms are often marked by a primary surface low developing over the Gulf of Mexico, and propagating northeastward along the Atlantic coast. Cyclogenesis is triggered by the outbreak of Arctic air moving
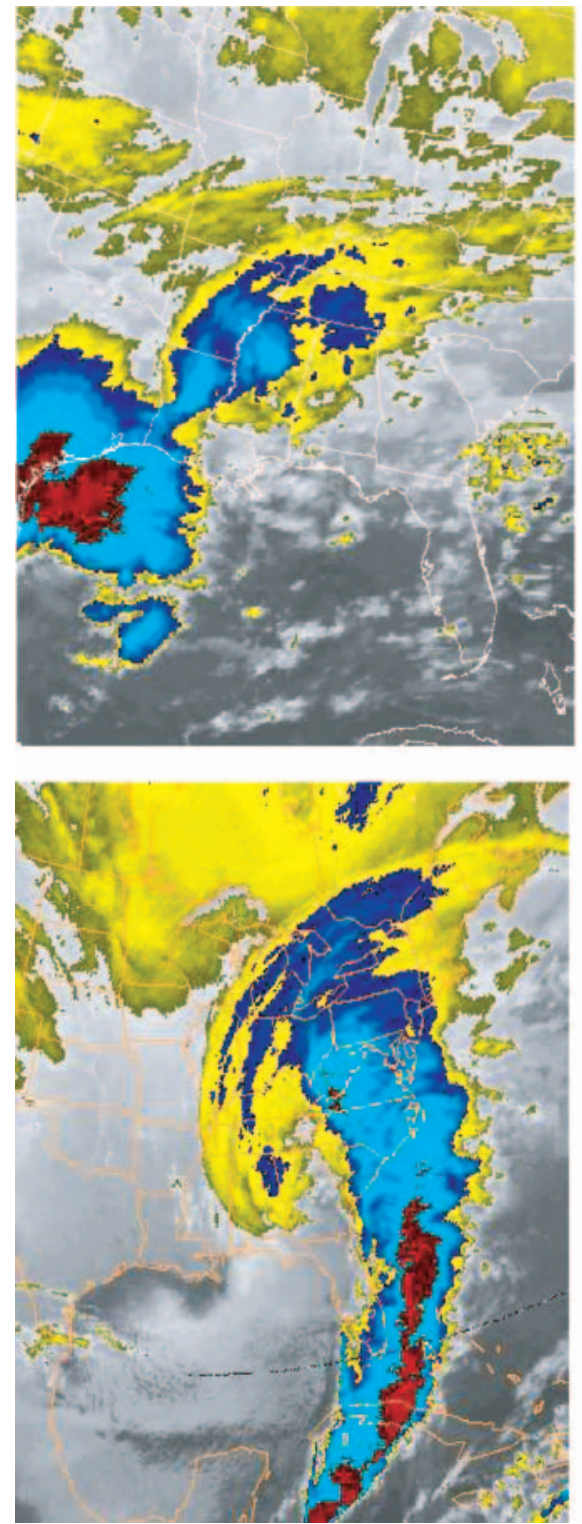
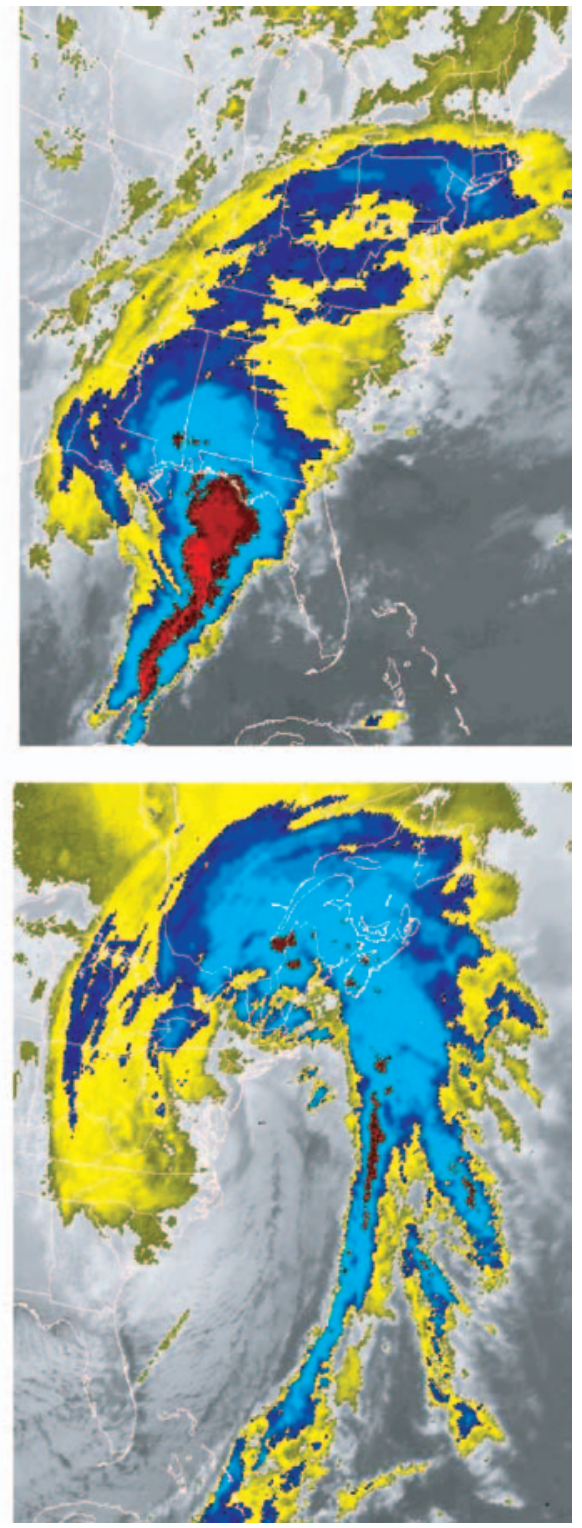

Fig. 3. Sequence of GOES7 images from 12Z, 12th of March 1993 to 00Z, 14th of March 1993 in the infrared channel with a horizontal resolution of $8 \mathrm{~km}$ (Source: COMET 001 data). The colors are an indication of cloud top temperature, and therefore of cloud height, rising from yellow via blue to red 
southward from the Canadian prairies, which meets warm air over the Gulf of Mexico and develops a baroclinic zone. The rapid deepening of the cyclones off the Carolina coast is the result of the tight thermal gradient that forms between the cold continental air and the warm air above the Gulf Stream (Cione et al. 1993). In general, heavy snowfall occurs to the north and northwest of the surface low located downwind of an upper-level trough approaching the East Coast. The cyclone interacts with a strong surface anticyclone over the northeastern US or eastern Canada, which provides the low-level source of cold air. The northward advection of warm, moist air and its ascent over colder air to the north of the surface low transports moisture into the region of the largest ascent. Those common features are illustrated by the conceptual model shown in Fig. 1 of Uccellini and Kocin (1987).

\subsection{The storm of the century}

\subsubsection{Introduction to the case}

From 12-14 March 1993, one of the most intense East Coast storms of the 20th century (hereafter referred to as SS93) hit much of the eastern US leading to large damage and the most widespread disruption of air travel in the history of aviation (Kocin et al. 1995). Due to its striking occurrence, it is furthermore one of the best documented events of this kind in recent decades. Figure 3 shows a sequence of GOES-7 infrared satellite images of the developing storm.

Some diagnostic studies of the storm and the quality of the different forecast systems were carried out by Uccelini et al. (1995) and Caplan (1995). They showed that the main features of the storm, and its planetary-scale developments were accurately predicted by different forecast models as much as 5 days in advance. However, there were significant underestimations of the rate of intensification in the incipient stage of the system in many forecast models (Gilhousen 1994; Dickinson et al. 1997).

Observational studies were carried out for example by Kocin et al. (1995) and Forbes et al. (1993). Huo et al. (1995) investigated the importance of different mechanisms for the development of SS93 with the mesoscale version of the Canadian Regional Finite-Element (RFE) model. They found that the jet-induced secondary circulation was important during the cyclone's incipient stage, whereas the final intensity of the storm was mainly determined by the latent heating in the rapid development phase of the system. Once the latent heating became dominant, the jet-induced circulation provided a favorable environment within which warm and moist air was transported into the warm-frontal zone.

SS93 developed along a stationary front from the western Gulf of Mexico to southern Georgia, which separated cold dry continental air from warm moist air over the Gulf of Mexico. During its development, remarkably low surface temperatures and sea level pressures as well as strong tendencies were measured in many regions of the southeastern and Middle Atlantic parts of the US (Kocin et al. 1995). The storm drew much of its energy from the strong thermal contrast between the cold continent and the warm ocean. This thermal contrast was accompanied by jet stream wind speeds in the upper troposphere exceeding $45 \mathrm{~ms}^{-1}$ at many stations across the northeastern US. A jet stream with maximum winds of $60 \mathrm{~ms}^{-1}$ at $300 \mathrm{hPa}$ was associated with the confluent flow over the northeastern US (Forbes et al. 1993). During the development, a second jet streak over the southeastern US developed, and merged with the existing northern one, in accordance with the conceptual model of Uccellini and Kocin (1987).

During the following days the cyclone moved to the southern tip of Greenland and further to Iceland, where it became stationary for a few days. As a classic "Icelandic low" it steered the following disturbances over the Atlantic before it dissipated slowly after the 19th of March off the West Coast of Norway.

\subsubsection{Representation of thermodynamics in the model simulation}

Figure 4 compares the ERA15 and ECHAM4 simulated tracks of the cyclone with an observation taken from Kocin et al. (1995). It shows the general ability of the ECHAM4 model to reproduce the general synoptic situation. The simulated cyclone crossed the Gulf of Mexico and Florida and moved, further deepening (Fig. 5), northeastward along the East Coast of the US. 


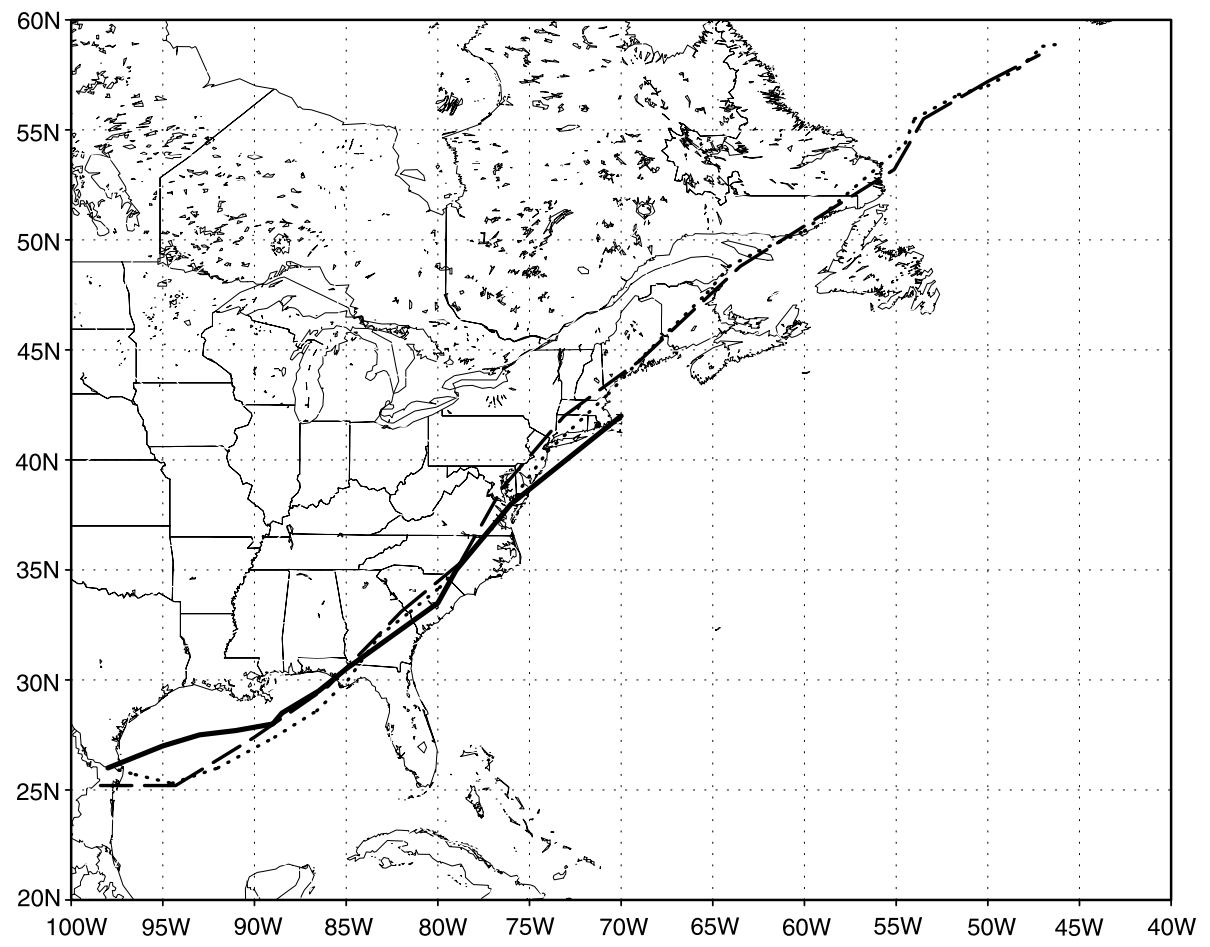

Fig. 4. Path of the cyclone between the 12th and 15th of March 1993 in the adjusted ECHAM4 simulation (dashed), ERA15 (dotted), and observations (solid). The observed positions were taken from Kocin et al. (1995). The temporal resolutions are 6 hours (ERA15) and 3 hours (ECHAM4)
Although the surface pressure was adjusted to ERA15, small differences in the representation of the cyclone location occur between the two models. This is investigated more closely further below, where the representation of other surface variables is described in more detail. The different tracks in the model simulations and the observation over the Gulf of Mexico are expected to be caused by a lower amount of observational data fed into ERA15 over the ocean, from which the forcing data for the relaxation is calculated. It is therefore considered as an initialization prob- lem. This is supported by Gilhousen (1994) who found several indications for a deeper than predicted development in buoy data collected over the Gulf of Mexico that was not used in the ECMWF assimilation system. To be able to separate between initialization and parametrization errors, we focus therefore mainly on comparisons of the two model products using ERA15 as benchmark for the performance of ECHAM4.

In Fig. 5, the temporal evolution of the surface pressure of the developing system in ECHAM4, ERA15, and an observation taken from Kocin

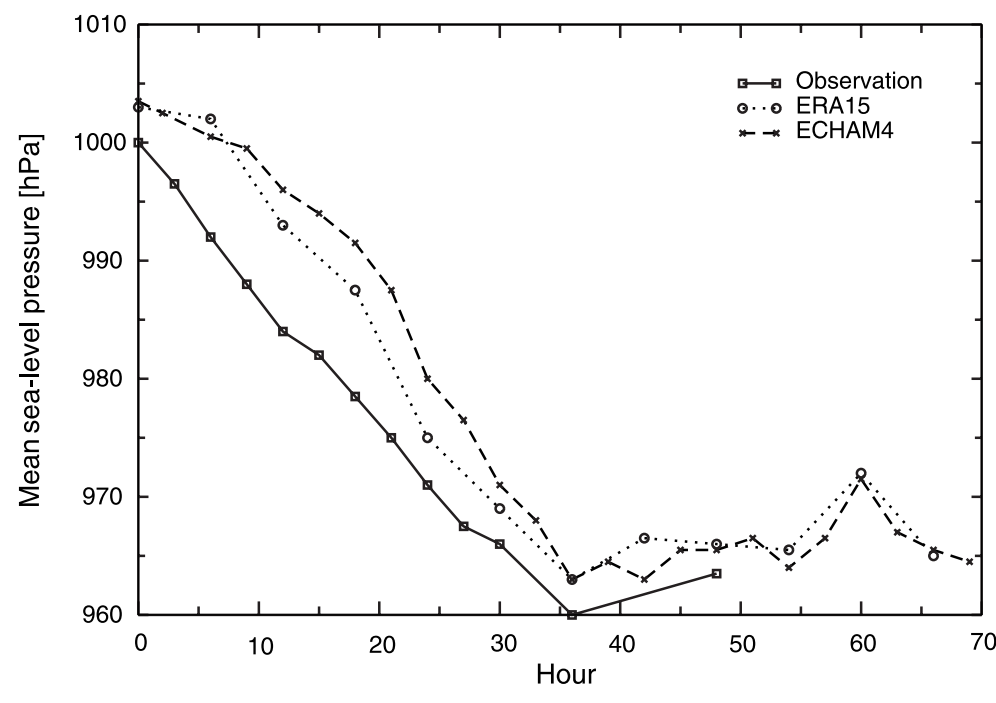

Fig. 5. Temporal development of the mean sealevel pressure $[\mathrm{hPa}$ ] between the 12th and 15th of March 1993 in the adjusted ECHAM4 simulation (dashed, crosses), the ERA15 (dotted, circles), and observations (solid, squares). The observed values were taken from Kocin et al. (1995). The temporal resolutions are 6 hours (ERA15) and 3 hours (ECHAM4) 
et al. (1995) is shown. The intensification is slightly weaker in the ERA15 and ECHAM4 simulations as compared to the observation over the Gulf of Mexico, and slightly stronger when the cyclone reaches the southeastern US, corresponding to the observations of Gilhousen (1994) mentioned above. This retarding of the cyclogenesis is more pronounced in the ECHAM4 simulation as compared to ERA15. A possible explanation is that the surface temperature is not adjusted with ERA15 data. Instead, the temperature is only adjusted at the model levels with the lowest model level being at about $30 \mathrm{~m}$ above surface. The models use different parametrizations for land surface and boundary layer processes, leading to different consistent thermodynamical states, even if the surface pressure is forced to the re-analysis. More details are given further below, where the representation of other surface fields in the two model simulations is compared. The simulated cyclones, in ECHAM4 as well as in ERA15, reach their lowest core pressure of $963 \mathrm{hPa}$ on the 14th of March at 6 UTC, slightly higher than the observed $960 \mathrm{hPa}$. The location of the low in the two simulations is slightly different. As indicated by the tracks and the temporal evolution of the core surface pressure, the system develops slightly differently in the two model simulations although the surface pressure is an adjusted prognostic variable. The development of the system is slightly stronger in ERA15. However, keeping in mind the relatively coarse resolution, the representation in the model simulations is very good.
To compare the intensification of the modeled cyclone with the real development, Fig. 6 shows the recorded temporal evolution of the surface pressure in Tallahassee, Florida with the tendencies for the same grid boxes in the adjusted ECHAM4 simulation and ERA15. The lowest core pressures in the model simulations are about $10-15 \mathrm{hPa}$ higher than observed. This is expected to be caused by three reasons. First, the intensification rate during the first hours of development of the system is weaker than observed. Second, the models use a coarse resolution of $1.125^{\circ}$. Finally, the model pressure values in Fig. 6 represent grid box averages, whereas the observation is a point measurement. One has to keep in mind, that the models write output only every 3 hours (ECHAM4) and 6 hours (ERA15). An exact determination of the time of the lowest surface pressure is therefore not possible, nor a comparison of the timing. However, it appears, that the timing is slightly different between the two model simulations although the surface pressure is an adjusted prognostic variable. This timing difference is expected to be caused by an apparently stronger drag at the surface in ERA15 whose consequences are also visible in the surface wind field discussed further below. Nevertheless, keeping in mind the coarse horizontal resolution the model representations are very good.

In the following paragraphs different meteorological fields are compared for three time steps during the development of SS93. They represent major phases of the cyclone life cycle

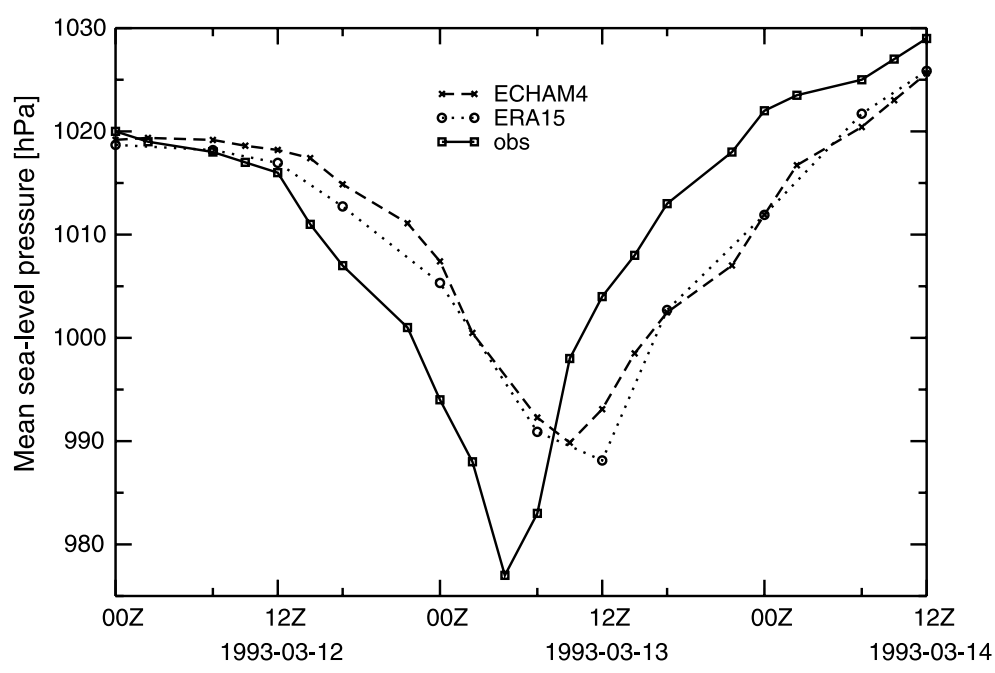

Fig. 6. Comparison of the observed temporal evolution of the surface pressure (solid, squares) during the passage of SS93 for Tallahassee, Florida with the tendencies occurring in the corresponding grid box of the adjusted ECHAM4 (dashed, crosses), and ERA15 (dotted, circles) simulations. The observations were taken from Kocin et al. (1995). The temporal resolutions are 6 hours (ERA15) and 3 hours (ECHAM4) 


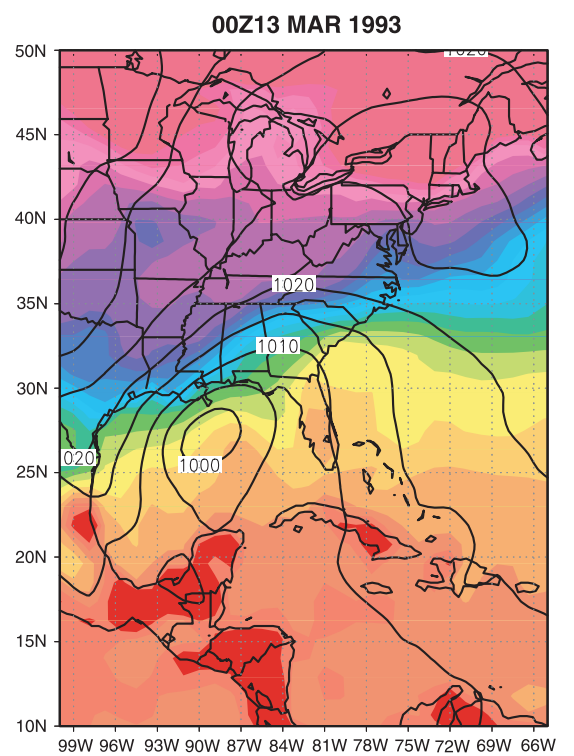

O0Z13 MAR 1993

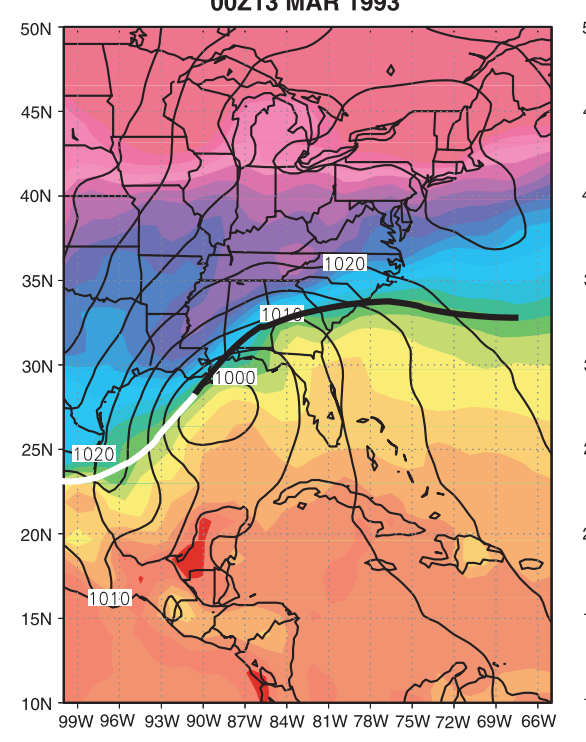

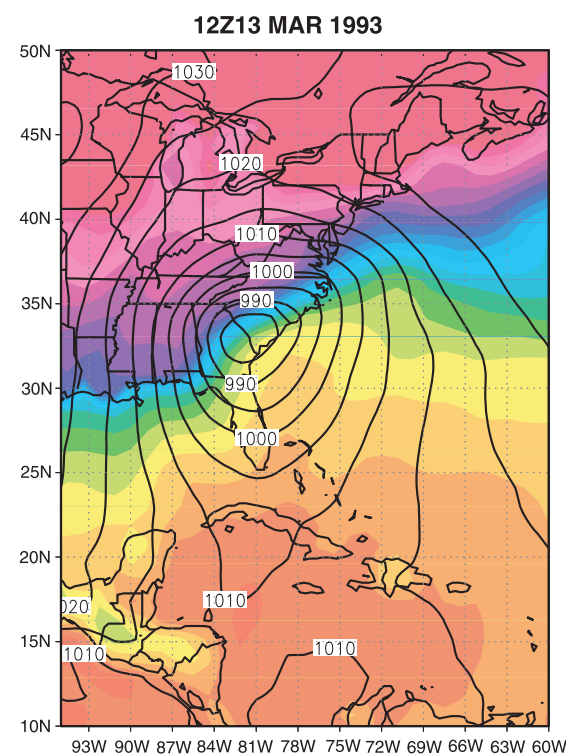

$12 Z 13$ MAR 1993

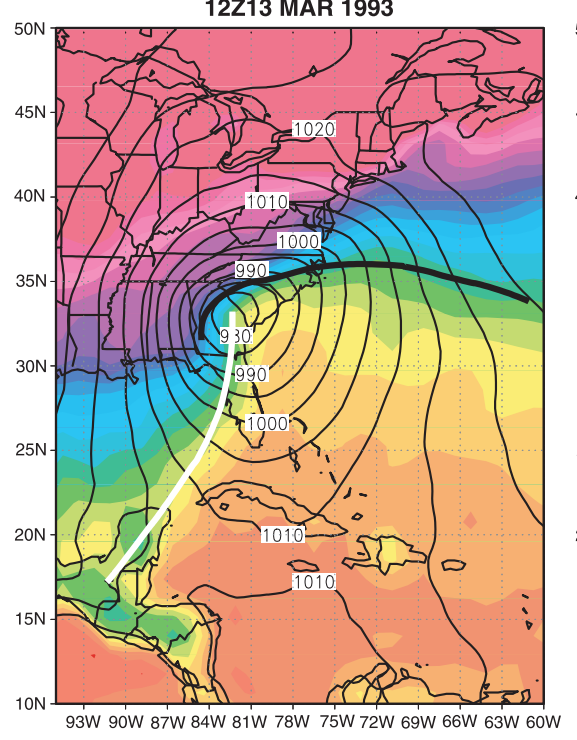

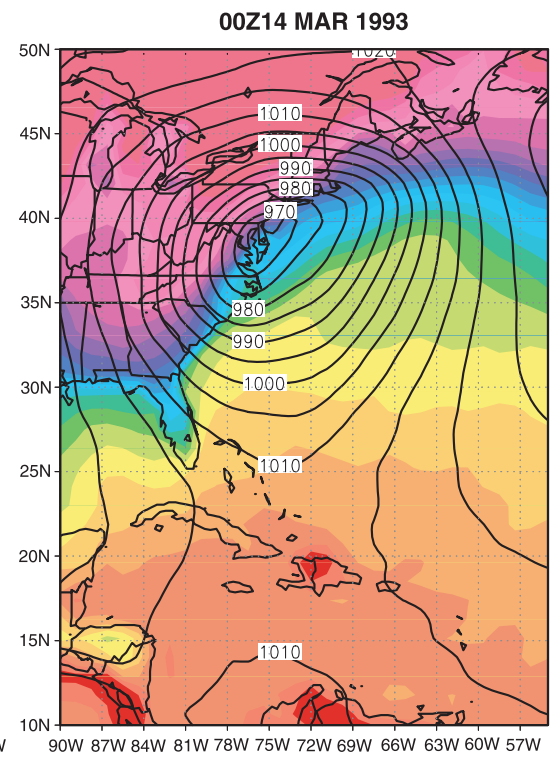

OOZ14 MAR 1993

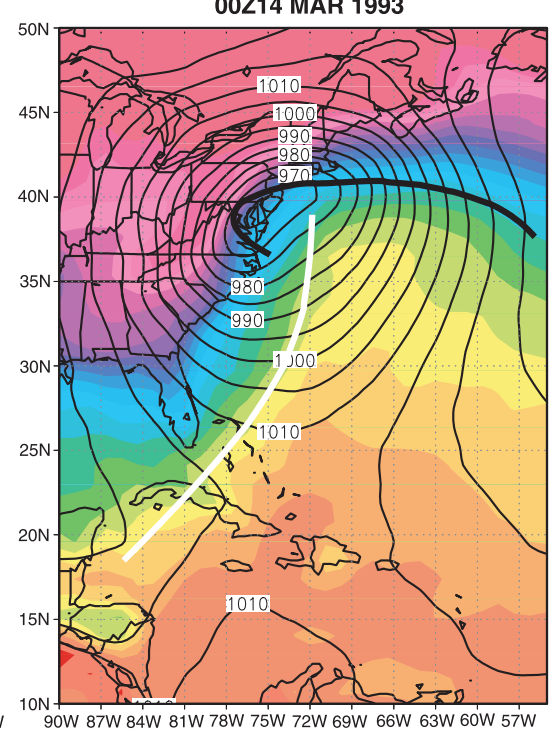

$-8 \quad-4$

4

8

$12 \quad 16 \quad 20$

$24 \quad 28$

Fig. 7. Development of the $2 \mathrm{~m}$ temperature $\left[{ }^{\circ} \mathrm{C}\right]$ (shaded) between the 13th and 14th of March 1993 in the adjusted ECHAM4 T106 simulation (top) and ERA15 (bottom). For ERA15 the lines show the estimated positions of the cold front (white) and the warm front (black). Isolines show the mean sea level pressure [hPa]

as described in the conceptual cyclone model of Shapiro and Keyser (1990).

Figure 7 shows the development of the $2 \mathrm{~m}$ temperature field in the ECHAM4 simulation and ERA15. Whereas only small differences occur over large regions of the ocean, the discrepancies are larger over land on the warm side of the developing system, especially over Florida, Middle America and the Caribbean islands, where the temperature difference between the two models reaches values of 2 to $4{ }^{\circ} \mathrm{C}$. Reasons for this differences over land are mainly different parametrization schemes for land surface and boundary layer processes used in the two models. The $2 \mathrm{~m}$ temperature as well as the $10 \mathrm{~m}$ wind speed discussed below are strongly influenced by the surface fluxes. In ERA15 as well as ECHAM4, the near-surface fields are calculated from the results at the lowest model level and the surface. The necessary transfer coefficients are calculated from Monin-Obukhov similarity theory, relating them to the gradients of the variables 
at the lowest model level. However, ERA15 uses different coefficients in stable regimes, or even different methods as in unstable regimes (Troen and Mahrt 1986). Another reason for the occurring differences in the $2 \mathrm{~m}$ temperature field over the ocean is that ECHAM4 and ERA15 uses different versions of the same sea surface temperature data set (Reynolds et al. 1994). ERA15 uses the original weekly averages, whereas ECHAM4 uses monthly averages. This leads to a slower reaction of the $2 \mathrm{~m}$ temperature field to an atmospheric forcing in the ECHAM4 simulation, and contributes to the higher $2 \mathrm{~m}$ temperatures over off-shore regions of the Gulf of Mexico and the western Atlantic.

The coefficients used to calculate the vertical exchange in stable regimes leads to a stronger vertical exchange in ERA15 as compared to the set of coefficients used in ECHAM4. This leads to a stronger influence of the surface on the lower part of the boundary layer, describing many of the occurring differences between the two model representations in the $2 \mathrm{~m}$ temperature field as well as the $10 \mathrm{~m}$ wind field discussed below. Together with the stronger surface wind, this leads to systematically lower temperatures over off-shore regions of the Gulf of Mexico and the Atlantic in ERA15. The stronger daily cycle of the $2 \mathrm{~m}$ temperature, most clearly seen over middle America, can also be explained by the stronger vertical exchange. In the warm sector of the developing system, the differences between the two models grow during the development. At 00Z 14th of March warmer air is advected further to the north in ERA15. Another reason for these differences is likely the slightly stronger development of the cyclone in the incipient stage of the system in ERA15 leading to a stronger northward transport of warm air to the east and a stronger southward transport of cold air to the west of the developing cyclone (compare horizontal surface pressure gradient in Fig. 7 with the temporal evolution of the cyclone core surface pressure in Fig. 5).

As seen in Fig. 7, the frontal boundaries and large-scale temperature advection fields are well reproduced in the two model simulations as compared to the conceptional model of Uccellini and Kocin (1987) and other observations presented in the literature (e.g., Kocin et al. 1995, Uccelini et al. 1995). The different phases of the conceptual cyclone model of Shapiro and Keyser (1990) can be clearly identified and the development of the remarkable cold front is well simulated in both model representations.

In contrast to the situation found for the developing storm, the differences of the $2 \mathrm{~m}$ temperature between ERA15 and ECHAM4 are generally small for the North Atlantic blocking situation (not shown). This is explained by the uniform temperature and moisture conditions over the ocean surface causing only small differences even if different representations of the surface and boundary layer processes are used. The same is true for the representation of the $10 \mathrm{~m}$ wind field.

Figure 8 compares the representation of the $10 \mathrm{~m}$ wind field in the two simulations. Here, as in the $2 \mathrm{~m}$ temperature field, pronounced differences occur. Although not forced to a climatology, the representation of the surface wind field is strongly influenced by the surface temperature field. Therefore, differences between ECHAM4 and ERA15 are not surprising. At the beginning of the development, the wind fields are very similar with stronger winds in ERA15 to the west of the developing cyclone. This is caused by the stronger pressure gradient to the west of the developing low in the incipient stage in ERA15. As for the $2 \mathrm{~m}$ temperature field, the differences between the two model simulations grow during the development. The wind velocities over land decrease to systematically lower values in ERA15 as compared to the ECHAM4 simulation. This is, on the one hand, explained by stronger vertical fluxes caused by the differences in the surface parametrization scheme mentioned above, decelerating the horizontal flow. On the other hand, this indicates that larger surface roughnesses are used in ERA15. Since the model used to prepare ERA15 is a numerical weather prediction model, it is avoided to force it towards its climatology. Therefore, an operational soil parametrization scheme developed by Viterbo and Beljaars (1995) is used. ECHAM4, on the other hand, uses climatological values derived from a U.S. Navy high-resolution data set.

At 00Z 14th of March, a clear separation of two regions with high surface winds is realistically simulated by ERA15. They are separated by the cold front where convergence reduces the horizontal motion at cost of stronger vertical motion. This results in a sharper representation of the frontal structures in ERA15. 

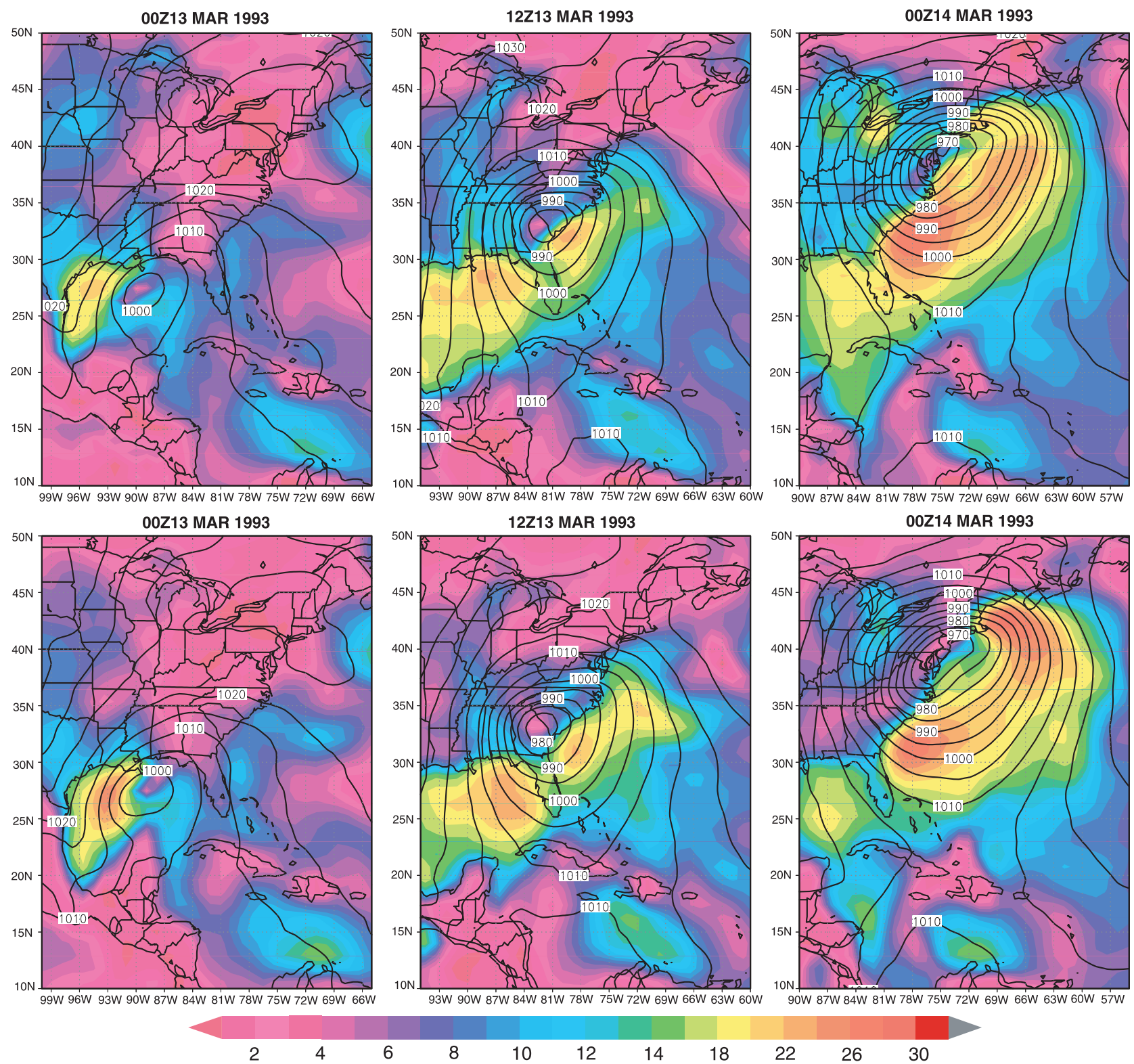

$6 \quad 8$

$10 \quad 12$

$14 \quad 18$

22

26

30

Fig. 8. Development of the $10 \mathrm{~m}$ horizontal wind velocity $[\mathrm{m} / \mathrm{s}]$ (shaded) between the 13 th and 14 th of March 1993 in the adjusted ECHAM4 T106 simulation (top) and the ERA15 (bottom). Isolines show the mean sea level pressure [hPa]

Figure 9 compares the vertical velocity fields at $500 \mathrm{hPa}$ of the two simulations for the three timesteps. The coarse frontal features with upward motion in the cold front and especially the cloud head region to the north and northeast of the surface low, where large amounts of moist near-surface air is lifted to the middle and upper troposphere, are well simulated in both model simulations. Furthermore, the subsidence behind the cold front where stratospheric air is intruded into the troposphere in the so-called "tropopause-fold", is generally realistically simulated.
The occurring vertical velocities appear small. However, one has to note that they represent averages from $120 \times 120 \mathrm{~km}^{2}$ grid boxes. The frontal structures, especially the developing cold front, are more pronounced in ERA15. This is true although the divergence, directly responsible for the representation of the vertical motion, is an adjusted prognostic variable. Comparison of the horizontal divergence fields at different levels illustrates that ERA15 simulates stronger divergences as well as convergences, which directly causes stronger vertical velocities via the conti- 

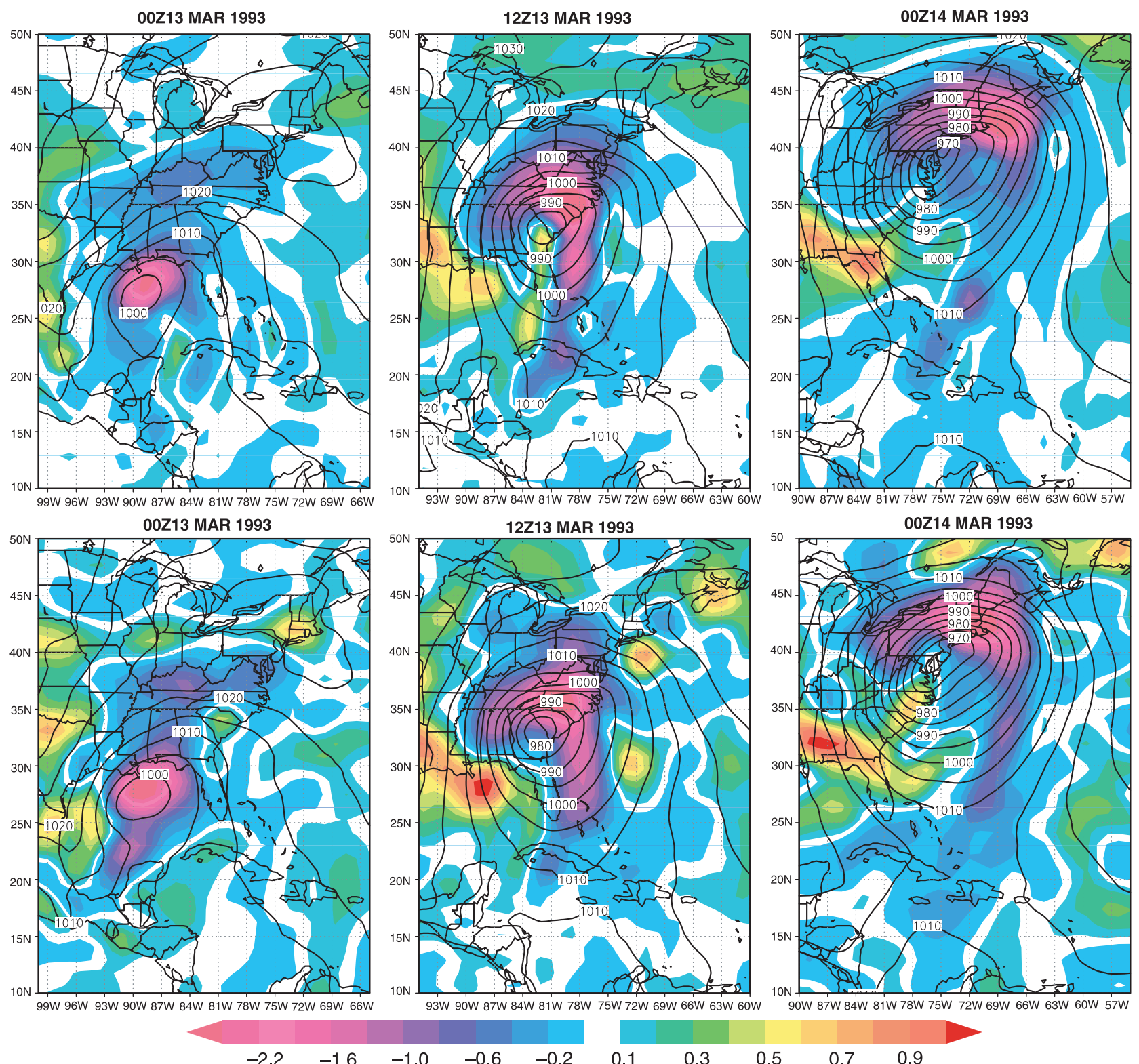

Fig. 9. Vertical wind velocity $[\mathrm{Pa} / \mathrm{s}]$ (shaded) at $500 \mathrm{hPa}$ of the adjusted ECHAM4 simulation (top row) and ERA15 for three timesteps during the development of SS93. Isolines show the mean sea level pressure [hPa]

nuity equation. Especially in the upper troposphere the divergence is clearly stronger. Figure 10 presents the horizontal divergence at $300 \mathrm{hPa}$. These differences indicate that ECHAM4 uses a different numerical treatment which dampens the forcing provided by ERA15.

Figure 11 compares the horizontal wind speed of the ECHAM4 simulation and ERA15 at $300 \mathrm{hPa}$. Although the general structure of the upper tropospheric wind field is similarly represented, and corresponds well to the conceptual model of Uccellini and Kocin (1987), differences occur in details. ERA15 exhibits stronger vertical as well as horizontal wind speeds (reaching values of more than $95 \mathrm{~m} / \mathrm{s}$ in the northern jet streak), explaining the stronger representation of the frontal structures. Especially the southern jet streak is stronger in ERA15 as compared to ECHAM4. A stronger horizontal circulation in the diffluence zone of a jet streak is associated with stronger divergences and therefore stronger vertical velocities. The jet streaks furthermore cover a larger region in ERA15 as compared to the ECHAM4 simulation. 

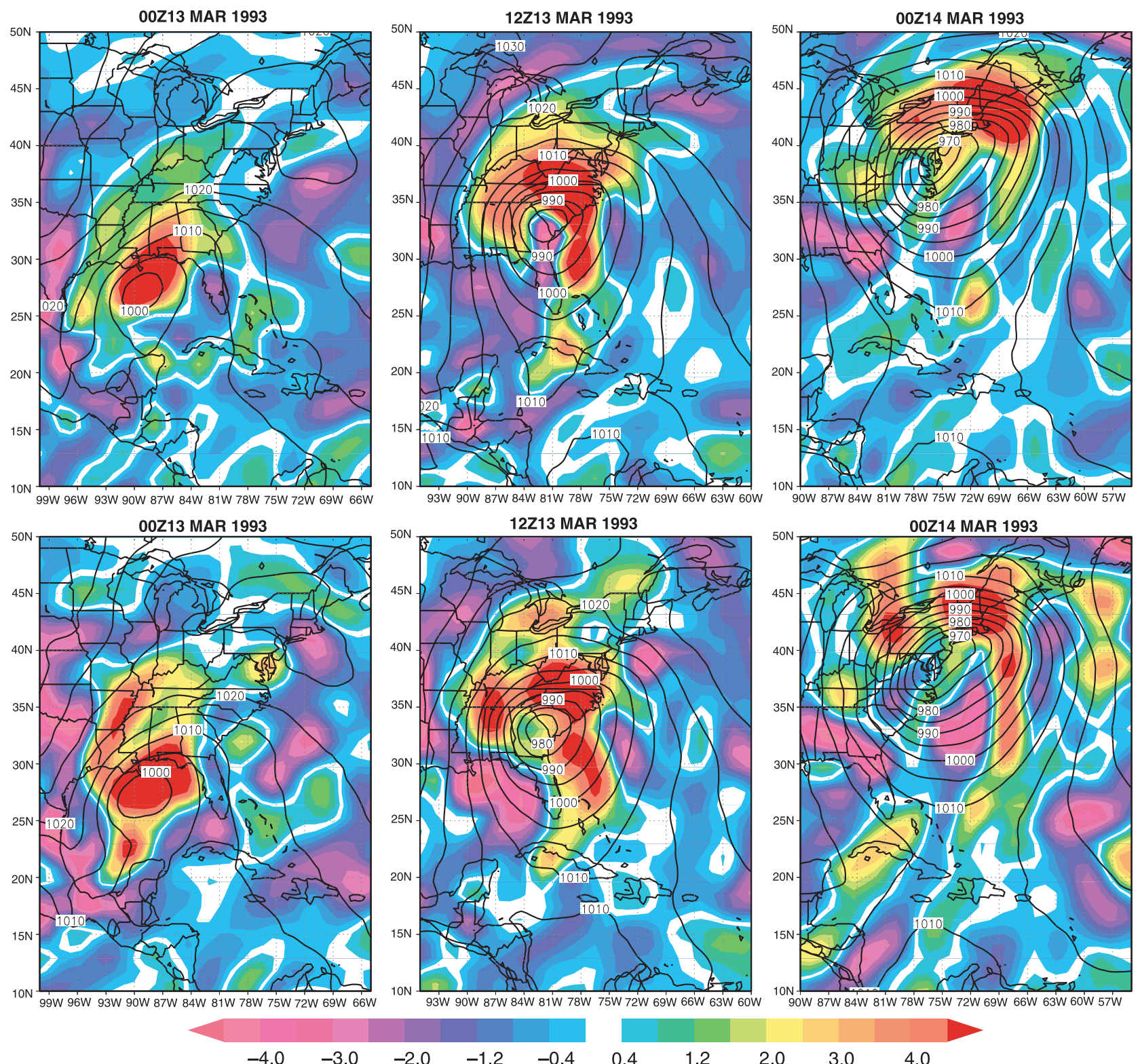

Fig. 10. Horizontal divergence $\left[10^{-4} \mathrm{~s}^{-1}\right]$ (shaded) at $300 \mathrm{hPa}$ of the adjusted ECHAM4 simulation (top row) and ERA15 (bottom) for three timesteps during the development of SS93. Isolines show the mean sea level pressure [hPa]

Figure 12 shows meridional cross sections of temperature differences (ECHAM4-ERA15), cutting the system at four different latitudes for 00Z, 14th of March 1993. The small plot in each panel indicates the location of the corresponding section. At first sight, the occurring differences appear surprisingly large keeping in mind that the temperature is an adjusted parameter. However, the temperature is strongly influenced by the evolving dynamics. As shown in Figs. 8 and 11, differences in the representation of the wind field occur. Therefore, differences in the representa- tion of the temperature field are to be expected. Largest deviations occur in the upper troposphere in frontal and post-frontal regions of the evolving cyclone. These variations are caused by differences in the representation of the jet streaks. ERA15 simulates systematically stronger jet streaks that partly cover larger areas as compared to ECHAM4, particularly the southern jet streak. In the lower troposphere, ECHAM4 appears to be systematically warmer in the region of the developing cyclone. Only to the north of the cyclone a colder lower troposphere is simu- 

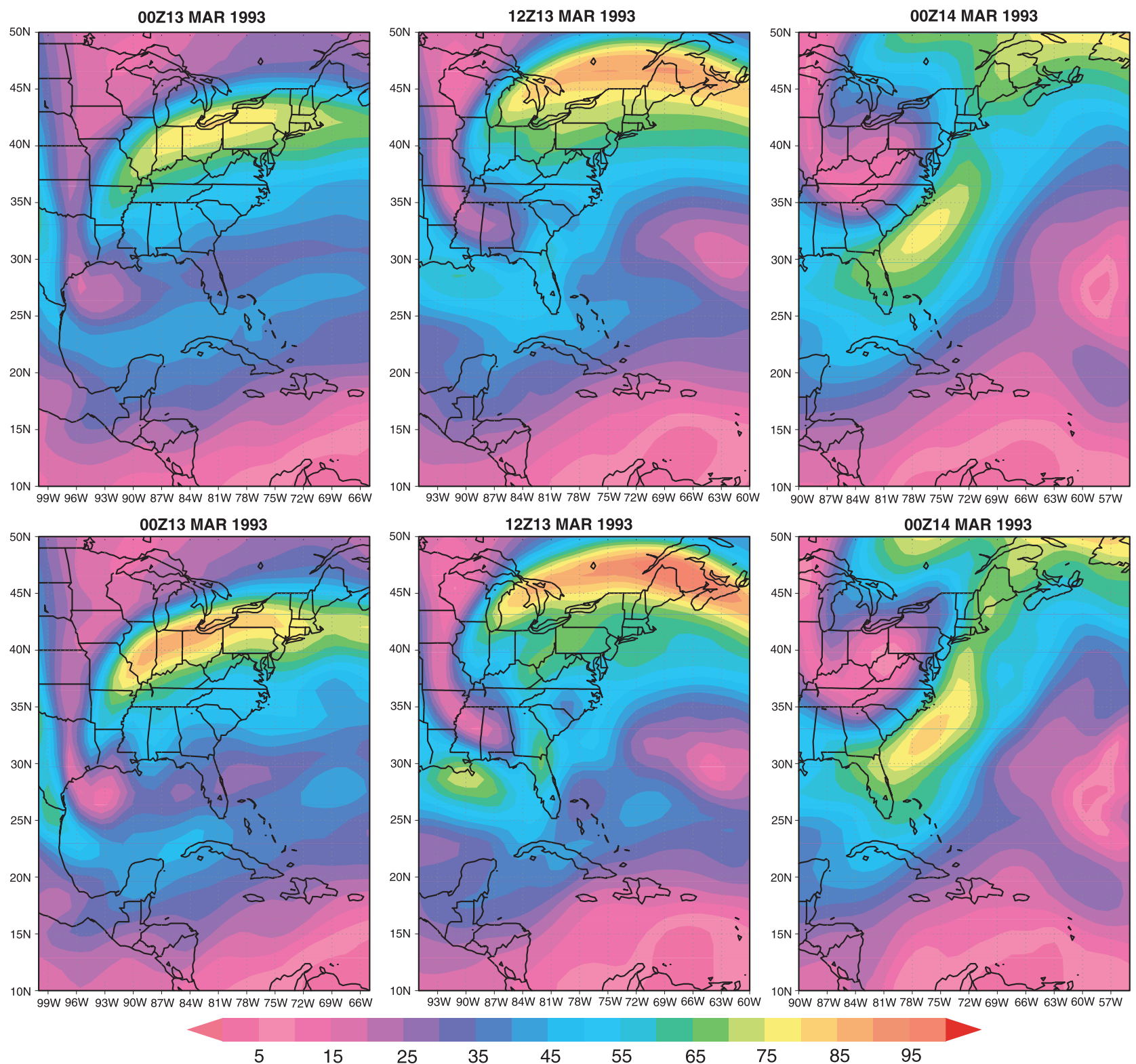

Fig. 11. Horizontal wind speed $[\mathrm{m} / \mathrm{s}]$ at $300 \mathrm{hPa}$ (shaded) of the adjusted ECHAM4 simulation (top row) and ERA15 (bottom) for three timesteps during the development of the East Coast storm

lated. In the middle troposphere the differences are smaller, and ECHAM4 appears to be slightly colder than ERA15. Apart from deviations in the dynamics, distinctions in the representation of clouds, and the corresponding release of latent heat can cause deviations in the representation of the temperature field. This is investigated in more detail in a companion paper using the introduced approach to validate the representation of clouds in ECHAM4.

Figure 13 shows the differences in the representation of the specific humidity field for the same four latitudes as in Fig. 12. As expected, noteworthy deviations are restricted to the lower and middle troposphere and mainly to the warm side of the developing system. In the middle troposphere, ECHAM4 tends to be moister than ERA15, whereas ECHAM4 tends to be too dry in the lower troposphere, especially in the northern part of the system. The wave-like pattern seen in the two southern section is caused by a slightly different location of the cold front in the two simulations. On the cold side of the system the moisture content is low. Furthermore, this region is dominated by downward motion, which also contributes to reduce the specific humidity. 

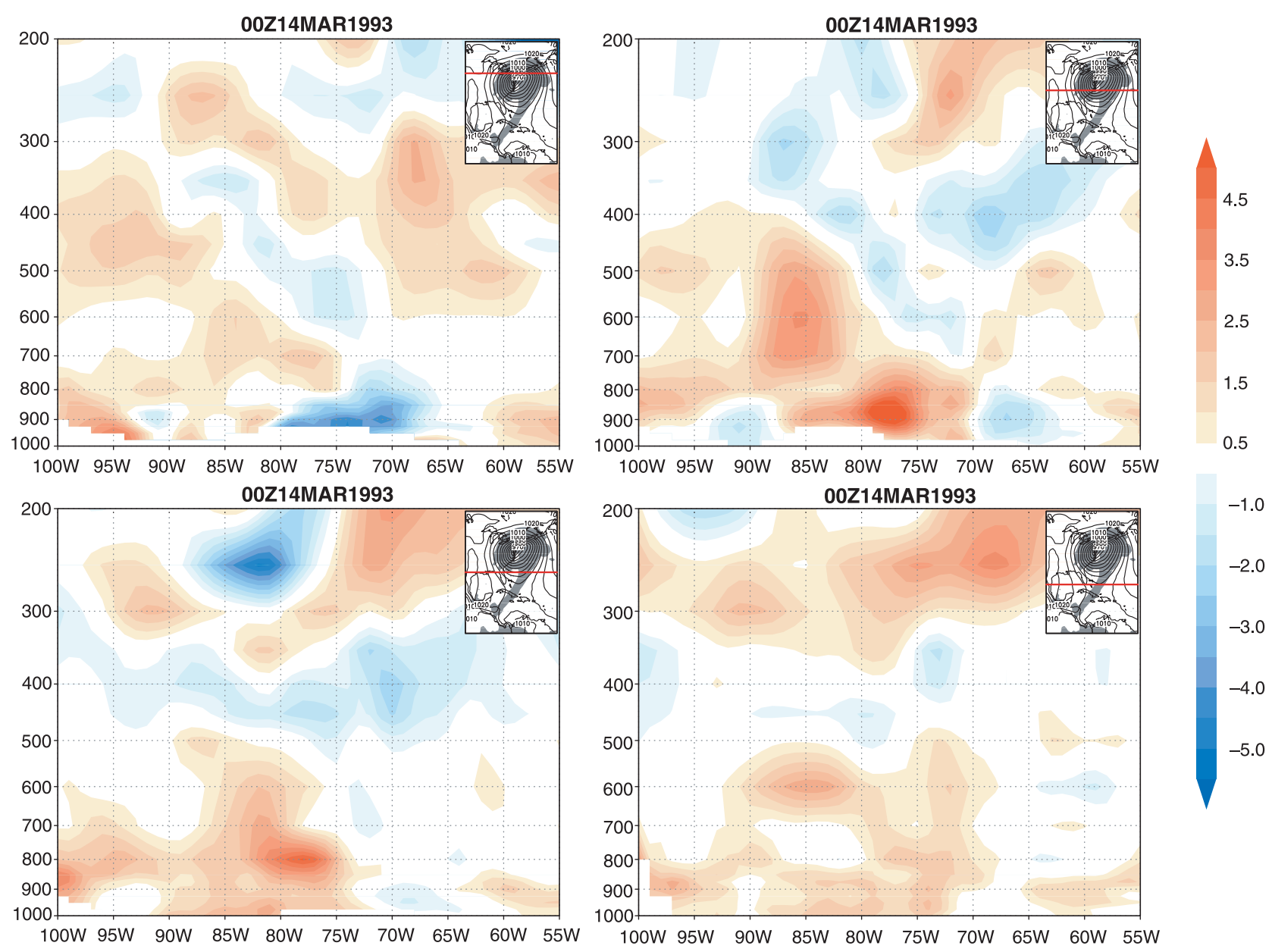

Fig. 12. Vertical cross section (longitude versus pressure) of the temperature difference (ECHAM4-ERA15) [K] (shaded) at four different latitudes for 00Z, 14th of March 1993. The locations of the sections are given in the small plots in the upper right corners

Sources of moisture in the middle troposphere are mainly horizontal and vertical advection. Large amounts of moisture are transported upwards from the lower troposphere on the eastern (warm) side of the system. On the cold (rear) side of the system subsidence from above and horizontal transport of cold continental air suppresses the transport of large amounts of moisture into the system.

Figures 14 and 15 show meridional cross sections of the vertical velocity cutting the system at the same latitudes used for the temperature and specific humidity differences for 00Z, 14th of March 1993. Although the vertical structure is very similar in both model representations, differences occur in detail. The northernmost section slices through the region of strongest updraft to the north and northwest of the surface low.
Both simulations show a large region of strong updraft between $65^{\circ} \mathrm{W}$ and $75^{\circ} \mathrm{W}$, penetrating vertically through the whole troposphere. The occurring vertical velocities are slightly stronger in ERA15. The section a few degrees south of the surface low through the cloud head reveals stronger differences in the representation of the vertical velocity field. Although the general structure is again similar, the occurring downdrafts are clearly stronger in ERA15, especially over the Appalachian mountains and the Great Plains on the rear side of the developing system. The frontal updraft is again slightly stronger in ERA15 as compared to ECHAM4. The next section to the south slices the system directly south of the cloud head. Here, ECHAM4 shows the stronger subsidence on the rear side of the system as compared to ERA15. The updraft in the cold front is on the 

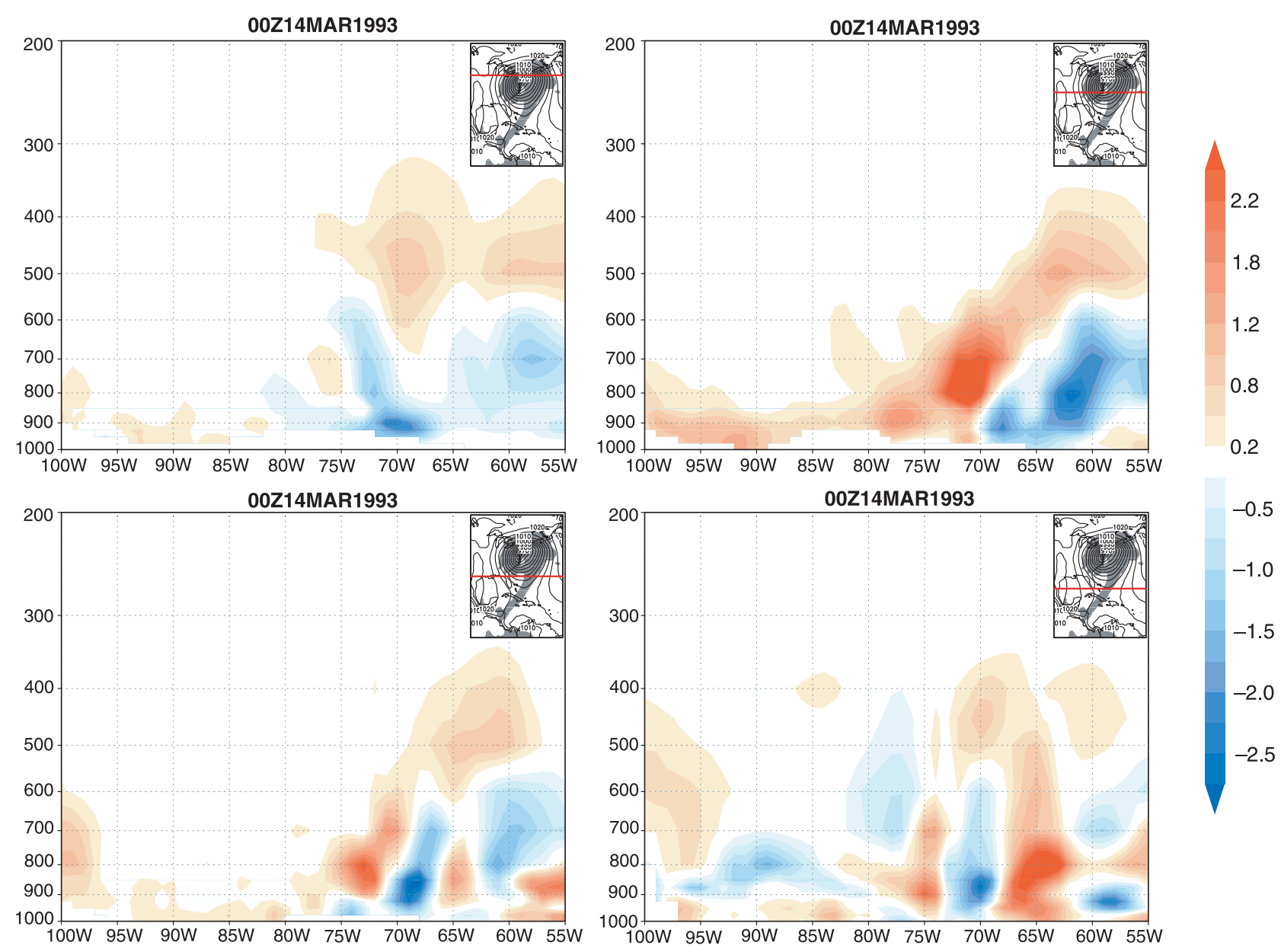

Fig. 13. As Fig 12, but for differences (ECHAM4-ERA) of the specific humidity [g/kg]

other hand clearly weaker. Furthermore, the vertical penetration of the updraft region, well established in ERA15, is restricted to the lower troposphere below $700 \mathrm{hPa}$ in ECHAM4. As compared to conceptional cyclone models (e.g., Shapiro and Keyser 1990), this behavior of ECHAM4 appears unrealistic and ERA15 shows a more consistent representation here. In the southernmost section through pre- and postfrontal regions of the cold front, ECHAM4 shows a sharper developed cold front, whereas the region of strong updraft covers a larger area in ERA15. In summary, marked differences occur in the representation of the vertical velocity field in the two model simulations. Generally, the upward motion in frontal regions, and the downward motion behind the cold front is stronger represented in ERA15, explaining the sharper representation of the fronts.

Cross sections of temperature for the blocking situation (not shown) are very similar in the
ECHAM4 and ERA15 simulations. Interestingly, also sections of specific humidity, which is not nudged in the ECHAM4 simulation, are remarkably similar in both model simulations. Reasons are probably the uniform and weak forcing from the surface and the predominant downward motion characteristic for such systems. For sections of the vertical velocity the same tendency as for the cyclone case is also visible here. Upward and downward motions are slightly stronger simulated by ERA15.

The most striking systematic difference between both model simulations and observations is the missing convective activity behind the cold front. Whereas ship reports and satellite images indicate severe precipitation events, no or only weak developments are found in the two model simulations, suggesting that the developing convective boundary layer is not well represented. This is illustrated in Fig. 16, which compares the cloudiness in three different cloud 

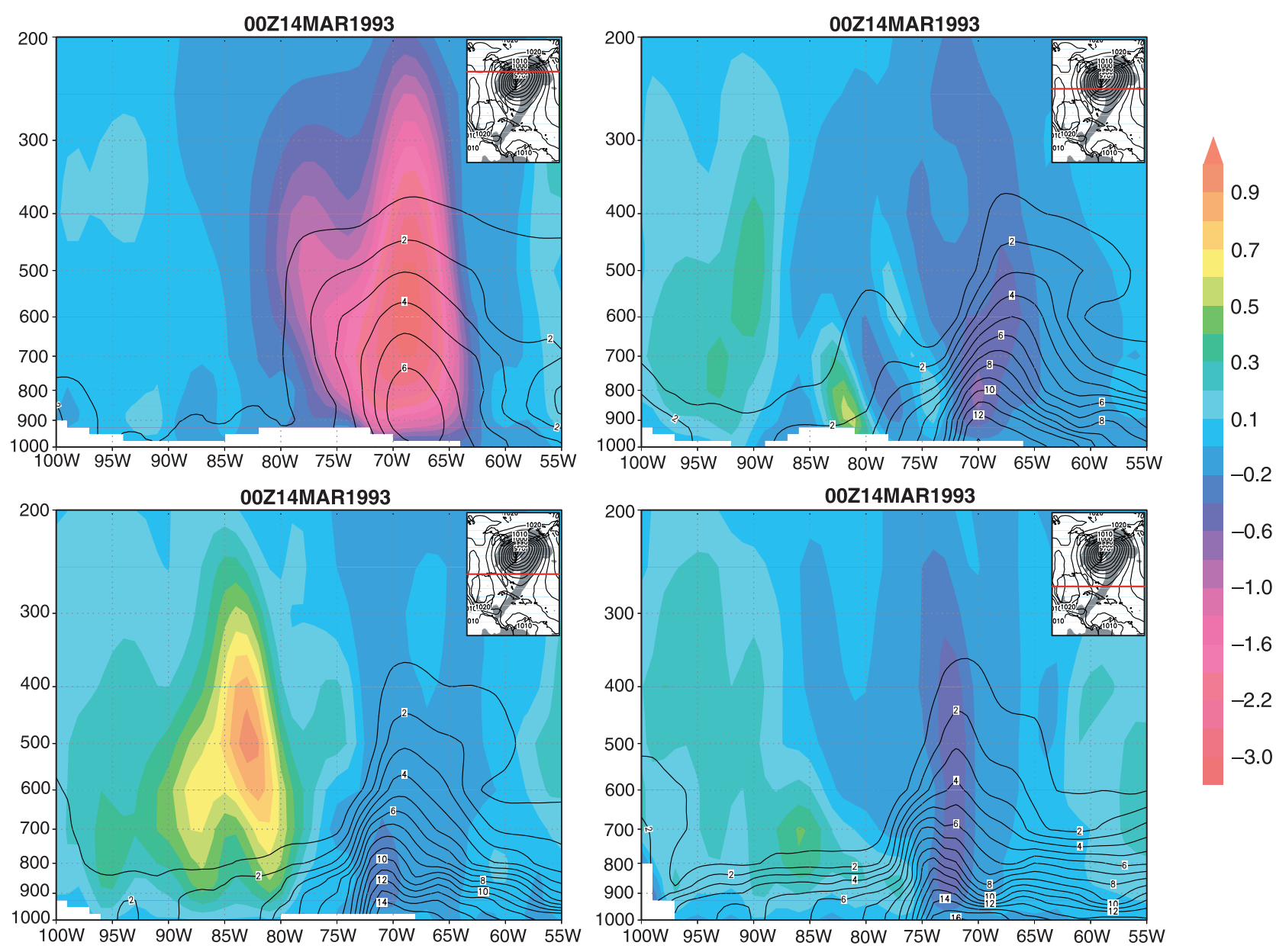

Fig. 14. Meridional cross sections of vertical velocity $[\mathrm{Pa} / \mathrm{s}]$ (shaded) and specific humidity $[\mathrm{g} / \mathrm{kg}]$ (contours) of the adjusted ECHAM4 simulation for 00Z, 14th of March 1993. The locations of the sections are given in the small plots in the upper right corners

levels for the two simulations. The left column of Fig. 16 compares the low-level cloudiness (0-2 km height) of ECHAM4 (top) and ERA15 (bottom) Both, ECHAM4 and ERA15 simulate low-level clouds in the boundary layer behind the cold front. This is different for mid-level clouds (2-6 km height) (middle column). In the ECHAM4 simulation no mid-level clouds occur outside of frontal regions, whereas ERA15 can partly reproduce the observed convection behind the cold front. The same is true for upper-level cloudiness (above $6 \mathrm{~km}$ height)(right column).

This erroneous representation can have several reasons. Both models use the same convection scheme. Therefore, it is probable that weaknesses in the convection scheme contribute to the erroneous representation of the convective boundary layer behind the cold front. ECHAM4 and ERA15 both use a massflux scheme based on
Tiedtke (1993) including changes from Nordeng (1994). It separates between shallow, midlevel and deep convection, but only one type of convection is allowed to be present in the grid box at one time step. Therefore, layered convection is not possible.

Weaknesses in the used cloud schemes can also contribute to the problems. Here, different schemes are used by the models. ECHAM4 uses a scheme based on Sundqvist (1978). It uses water vapor and cloud water as prognostic variables, and separates diagnostically between water and ice according to temperature. The fractional cloudiness in the grid box is related to the grid box mean relative humidity and the stability of the atmosphere. At relative humidities below $60 \%$ no clouds are developed in the ECHAM4 model. This assumption might be reasonable for long-term averages, but not for the simulation of 

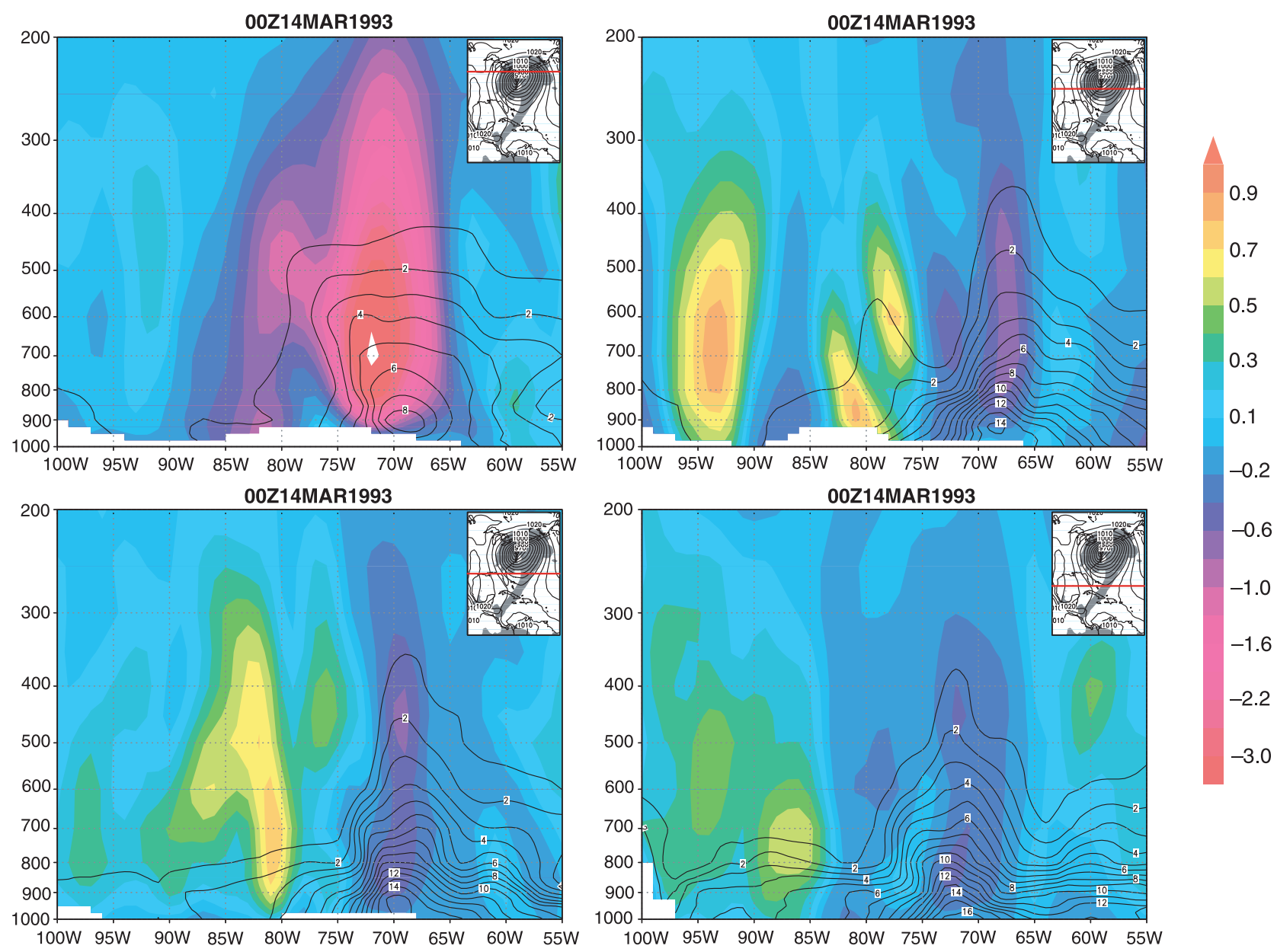

Fig. 15. Meridional cross sections of vertical velocity [Pa/s] (shaded) and specific humidity [g/kg] (contours) of ERA15 for 00Z, 14th of March 1993. The locations of the sections are given in the small plots in the upper right corners

single synoptic systems, where $10-20 \%$ cloud coverage is observed at relative humidities as low as 20\% (Walcek 1994). ERA15 uses a different cloud scheme from Tiedtke (1993). Here, in addition to water vapor and cloud water, the fractional cloud cover is calculated prognostically. This is expected to contribute to the slightly better representation of the cold front in ERA15. In both models, the convection and cloud schemes are linked by the detraining cloud water at the top of the convective cloud which is fed into the prognostic equation of cloud water in the cloud scheme.

Weaknesses in the boundary layer scheme can also contribute to the observed errors when the vertical transport of moisture from near surface layers up into the troposphere is too weak with the consequence that too little amounts of moisture are provided to the cloud and convection schemes. This can be caused by too strong sub- sidence compensating the frontal lifting and restricting the vertical transport of moisture to the well-mixed boundary layer.

The missing convective activity is not only a problem of ECMWF and ECHAM4 and their low model resolutions. Even with the much higher resolution of the regional climate model REMO (Jacob and Potzun 1997), this problem occurs (Klepp 2000; Jacob 2000). The underestimation of particularly mid-level clouds was also pointed out by Ryan et al. (2000), who compared the representation of a cold front in different models ranging from cloud-resolving to large-scale models. This indicates that either an important physical process, acting in reality, is not simulated properly by the models, or that wrong processes are simulated. Since convection and cloud processes are parametrized even in high resolution limited areas simulations, the weaknesses in the 

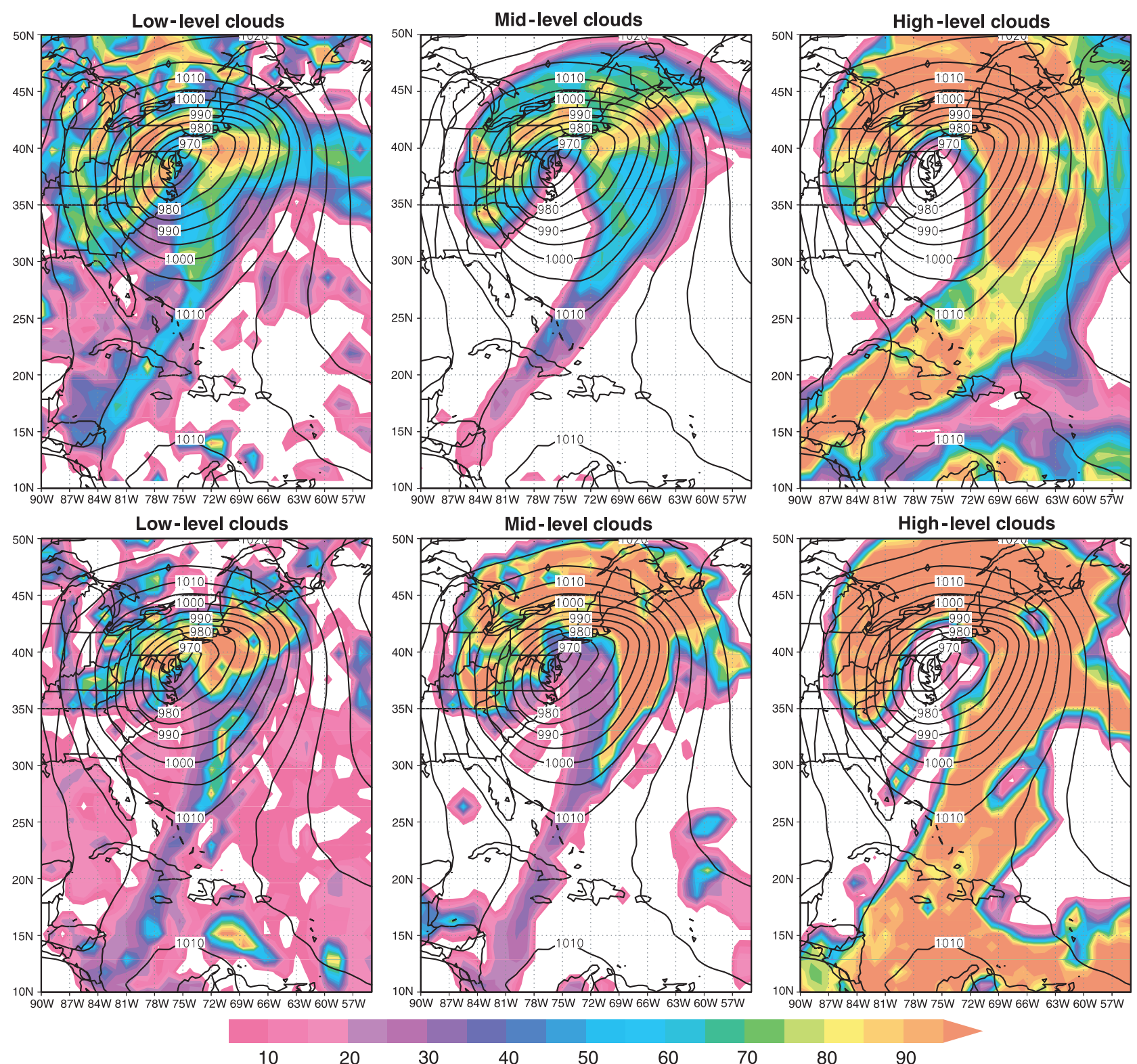

Fig. 16. Representation of low-level (left column, 0-2 km height), mid-level (middle column, 2-6 km height), and highlevel clouds (right column, above $6 \mathrm{~km}$ height) in ECHAM4 (top row) and ERA15 (bottom row) for 00Z, 14th of March 1993

schemes mentioned above are likely one of the causes of the problem.

Main finding by comparing the representations of the cyclone and the blocking high in the adjusted ECHAM4 simulation was that systems developing over wide regions with more or less constant temperature and moisture conditions are better represented in the adjusted model simulation. On the other hand, systems developing in synoptically active regions show larger differences to ERA15. This underlines the mentioned assumption that the representation of the surface conditions and the resulting vertical fluxes play a major role to determine the representation of such systems in the models.

\section{Conclusions}

In this paper, the representation of a single synoptic-scale weather system in a high resolution (T106) version of the ECHAM4 general circulation model was investigated. This was performed with a process-orientated method to validate such models, which has two advantages as compared 
to the more traditional climatological validation. Firstly, model errors can be more easily traced back to their causes since no temporal averaging to monthly or longer mean values is performed. Secondly, the model can be validated against observations collected during field campaigns. The latter provide quantities, such as cloud liquid water or other cloud properties which are not available as climatologies (Lohmann et al. 1999). In this paper, we focused on the representation of the model thermodynamics, whereas a detailed validation of the representation of components of the hydrological cycle in the ECHAM4 model, using this approach, is executed in a companion paper.

As case study we selected an extraordinary strong cyclone, which developed along the East Coast of the U.S.A. between the 12th and 14th of March 1993. To be able to compare the model simulation with observations from single synoptic systems, it is necessary to force the model to the observed state. In NWP models this is performed with a data assimilation scheme, which is not available for the ECHAM4 model. Therefore, a thermodynamical adjustment approach was chosen based on the Newtonian relaxation technique (nudging) (Krishnamurti et al. 1991; Jeuken et al. 1996). The quantities which were relaxed were vorticity, divergence, temperature, and the logarithm of surface pressure. The moisture field was not forced to avoid influences of the known spinup errors occurring in the moisture field of ERA (Kållberg 1997). The strength of the forcing is determined by an adjustment time scale for every variable. Here values suggested by Jeuken et al. (1996) were used. They were large enough to force the model dynamics to the observed state within a few days, but too small to remove typical features and errors produced by the parametrization schemes. The main advantage of this adjustment procedure, as compared to standard data assimilation schemes, is the more gradual forcing to the observed state which reduces the amount of meteorological noise introduced into the simulation. On the other hand, model and analysis errors are not explicitly used for the assimilation, but rather a tuned time scale is used during which the adjustment is performed.

Usually the error in numerical forecasts is caused partly by initialization errors and partly by errors in the model. The separation of these two error sources is a difficult task. To cope with this problem, the ECHAM4 simulation is mainly compared to ERA15, to which ECHAM4 is forced. This allows a relation of the occurring differences in the model results to causes in the used parametrization schemes.

The track of the cyclone is well represented in ECHAM4 as compared to ERA15 and observations taken from Kocin et al. (1995). However, small differences in position and intensity of the developing system occur. They can be mainly traced back to differences in the representation of the surface fluxes in the planetary boundary layer. Their different parametrizations lead to different balanced states in the two models.

The comparison of different surface variables, as $2 \mathrm{~m}$ temperature or $10 \mathrm{~m}$ wind field, and the parametrizations used in ERA15 and ECHAM4, revealed systematic differences in the representation of SS93. The representation of the surface variables is strongly influenced by the surface fluxes. Here, although the same framework for the parametrization scheme is used in ERA15 and ECHAM4, differences occurring in detail lead to systematic differences in the representation of the surface fields. For example, whereas the $2 \mathrm{~m}$ temperature is very similar over wide regions of the ocean, larger differences of 2 to $4 \mathrm{~K}$ occur over land on the warm side of the system. The development of the frontal structures is generally well represented in both model simulations with differences occurring in detail. The frontal structures are sharper represented in ERA15. A closer look into the representation of vertical velocity and horizontal divergence reveal that ERA15 simulates stronger surface convergence and especially stronger upper tropospheric divergence than ECHAM4, explaining the stronger vertical velocity. These differences occur although the divergence is an adjusted variable. This points to differences in the numerical treatment in the models that dampen the gradients in ECHAM4. In addition, the surface wind velocities over land, although very similar at the beginning of the development, are systematically lower in ERA15 in later stages of the development. Apart from the different vertical fluxes mentioned above, the surface is treated differently in the two model simulations. While ECHAM4 uses climatological values, ERA15, created with a numerical weather prediction model, uses an explicit approach to avoid to force the model to its climatology. 
The most striking systematic difference between the two model simulations and observations from satellite and ships is the missing (ECHAM4) or strongly underestimated (ERA15) convective activity behind the cold front. This is caused by the convection, cloud microphysics, or boundary layer schemes.

The previous sections showed that the introduced method is feasible to force the climate model ECHAM4 to the observed state. The model is capable to reproduce the selected synoptic situation, although different versions of the SST climatology of Reynolds et al. (1994) are used as lower boundary condition. This first step was necessary to show the feasibility of the proposed process-oriented validation approach. The next step, using this approach, is presented in a companion paper, where the representation of components of the hydrological cycle in the ECHAM4 model is investigated in detail.

\section{Acknowledgments}

We are grateful to Johann Feichter, Martin Stendel and Ingo Kirchner for their help in the preparation and debugging of the model for the simulations and for making available the necessary forcing files. Furthermore, Uwe Schulzweida and Luis Kornblueh are thanked for their tireless computational assistance.

\section{References}

Bengtsson L, Botzet M, Esch M (1995) Simulation of hurricane-type vortices in a general circulation model. Tellus 47A: 175-96

Bengtsson L, Hodges KI (2005) On the impact of humidity observations in numerical weather prediction. Tellus 57A: 701-708

Boyle J, Williamson D, Cederwall R, Fiorino M, Hnilo J, Olson J, Phillips T, Potter G, Xie S (2005) Diagnosis of community atmospheric model 2 (CAM2) in numerical weather forecast configuration at atmospheric radiation measurement sites. J Geophys Res 110: D15S15; DOI: $10.1029 / 2004 J D 005042$

Caplan PM (1995) The 12-14 March 1993 superstorm: performance of the NMC global medium range model. Bull Am Meteor Soc 76: 201-12

Chen C-T, Roeckner E (1997) Cloud simulations with the Max Planck institute for meteorology general circulation model ECHAM4 and comparison with observations. J Geophys Res 102: 9325-50

Cione JJ, Raman S, Pietrafesa LJ (1993) The effect of Gulf stream-induced baroclinicity on US east coast winter cyclones. Mon Wea Rev 121: 421-30
Dickinson MJ, Bosart LF, Bracken WE, Hakim GJ, Schultz DM, Bredrick MA, Tyle KR (1997) The March 1993 superstorm cyclogenesis: incipient phase, synoptic- and convective-scale flow interaction and model performance. Mon Wea Rev 125: 3041-72

Doms G, Förstner J, Heise E, Herzog HJ, Raschendorfer M, Reinhardt T, Vogel G (2005) A description of the nonhydrostatic regional model LM. Part II: Physical parameterizations. Technical report, German Weather Service, Offenbach, Germany

Doms G, Gassmann A, Heise E, Raschendorfer M, Schraff C, Schrodin R (2001) Parameterization issues in the nonhydrostatic NWP-model LM. In: ECMWF seminar proceedings: key issues in the parameterization of subgrid physical processes. 3-7 September 2001, European Centre for Medium Range Weather Forecasting, Reading, UK, pp. 202-52

Errico RM, Raeder K, Ehrendorfer M (2004) Singular vectors for moisture-measuring norms. Quart J Roy Meteorol Soc 130: 963-87

Forbes GS, Blackburn RM, Taylor PL (1993) “Blizzard of the century" - the storm of the 12-14 March 1993 over the eastern United States. Meteor Mag 122: 153-62

Fouquart Y, Bonnel B (1980) Computation of solar heating of the Earth's atmosphere: a new parameterization. Beitr Phys Atmos 53: 35-62

Gilchrist A (1971) An example of synoptic development in a general circulation model. Quart J Roy Meteorol Soc 97: 340-47

Gilhousen DB (1994) The value of NDBC observations during March 1993's "Storm of the Century". Weather Forecast 9: 255-64

Giorgetta M, Wild M (1995) The water vapour continuum and its representation in ECHAM4. MPI Report 162, Max Planck Institute for Meteorology, Hamburg, Germany

Grell GA, Dudhia J, Stauffer DR (1995) A description of the 5th generation Penn State/NCAR mesoscale model (MM5). NCAR Tech Note TN-398+STR, NCAR, Boulder, CO, USA

Heymsfield AJ (1977) Precipitation development in stratiform ice clouds. A microphysical and dynamical study. J Atmos Sci 34: 367-81

Hoke JE, Anthes RA (1976) The initialization of numerical models by a dynamic-initialization technique. Mon Wea Rev 104: 1551-56

Huo Z, Zhang D-L, Gyakum J, Staniforth A (1995) A diagnostic analysis of the superstorm of March 1993. Mon Wea Rev 123: 1740-61

Jacob D (2000) Personal communication

Jacob D, Potzun R (1997) Sensitivity studies with the regional climate model REMO. Meteorol Atmos Phys 63: 119-29

Jeuken ABM, Siegmung PC, Heijboer LC, Feichter J, Bengtsson L (1996) On the potential of assimilating meteorological analysis in a global climate model for the purpose of model validation. J Geophys Res 101: 16939-50

Kållberg P (1997) Aspects of the re-analysed climate. ECMWF Re-Analysis Project Report Series 2. European 
Center for Medium Range Weather Forecasts, Reading, UK

Kirchner I (1999) Personal communication

Klepp C (2000) Personal communication

Kocin PJ, Schumacher PN, Morales RF Jr, Uccellini LW (1995) Overview of the 12-14 March 1993 superstorm. Bull Am Meteorol Soc 76: 165-82

Krishnamurti TN, Xue J, Bedi HS, Ingles K, Oosterhof D (1991) Physical initialization for numerical weather prediction over the tropics. Tellus 43AB: 53-81

Krishnamurti TN, Bedi HS, Ingles K (1993) Physical initialization using SSM/I rain rates. Tellus 45A: 247-69

Lohmann U, McFarlene N, Levkov L, Abdella K, Albers F (1999) Comparing different cloud schemes of a single column model by using mesoscale forcing and nudging technique. J Climate 12: 438-61

Matveev LT (1984) Cloud dynamics. Atmospheric Science Library. D. Reidel Publishing Company, Dordrecht, $340 \mathrm{pp}$

McFarlane NA, Boer GJ, Blanchet J-P, Lazare M (1992) The Canadian climate center second-generation general circulation model and its equilibrium climate. J Climate 5: 1013-44

Miller MJ, Palmer TN, Swinbank R (1989) Parameterization and influence of sub-grid scale orography in general circulation and numerical weather prediction models. Meteorol Atmos Phys 40: 84-109

Moncrieff MW (1995) Mesoscale convection from a largescale perspective. Atmos Res 35: 87-112

Morcrette J-J (1991) Radiation and cloud radiative processes in the European centre for medium range weather forecasts forecasting system. J Geophys Res 96: 9121-32

Nordeng TE (1994) Extended version of the convective parameterization scheme at ECMWF and their impact on the mean and transient activity of the model in the tropics. Tech. Memo 206, European Centre for Medium Range Weather Forecasting, Reading, UK

Palmer TN, Shutts GJ, Swinbank R (1986) Alleviation of a systematic westerly bias in general circulation and numerical weather prediction models through an orographic gravity wave drag parameterization. Quart J Roy Meteorol Soc 112: 1001-31

Phillips TJ, Potter GA, Williamson DL, Cederwall RT, Boyle JS, Fiorino M, Hnilo JJ, Olson JG, Xie S, Yio J (2004) Evaluation of parameterizations in general circulation models - climate simulation meets weather prediction. Bull Am Meteor Soc 85(12): 1903-15

Reynolds RW, Rayner NA, Smith TM, Stokes DC, Wang W (1994) An improved in situ and satellite SST analysis for climate. J Climate 15(13): 1609-25

Rockel B, Raschke E, Weyres W (1991) A parameterization of broad-band radiative transfer properties of water, ice and mixed clouds. Beitr Phys Atmos 64: 1-12

Roeckner E, Rieland M, Keup E (1991) Modeling of cloud and radiation in the ECHAM model. In: ECMWF/WCRP Workshop on "clouds, radiative transfer and the hydrological cycle", 12-15 Nov 1990. European Centre for Medium Range Weather Forecasting, Reading, UK, pp. 199-222
Roeckner E, Arpe K, Bengtsson L, Christoph M, Claussen M, Diimenil L, Gior-getta M, Schlese U, Schulzweida U (1996) The atmospheric general circulation model ECHAM4: model description and simulation of the present-day climate. MPI Report 218, Max Planck Institute for Meteorology, Hamburg, Germany

Ryan B, Katzfey J, Abbs D, Jacob C, Lohmann U, Rockel B, Rotstayan L, Steward R, Szeto K, Tselioudis G, Yau M (2000) Simulations of a cold front by cloud-resolving, limited-area, and large-scale models, and a model evaluation using in situ and satellite observations. Mon Wea Rev 128: 3218-35

Shapiro M, Keyser D (1990) Fronts, jet streams and the tropopause. In: Newton CW, Holopainen E (eds) Extratropical cyclones: The Erik Palmen Memorial Volume. Am Meteor Soc, pp. 167-91

Stauffer DR, Seaman NL (1990) Use of four-dimensional data assimilation in a limited-area mesoscale model. Part I: experiments with synoptic-scale data. Mon Wea Rev 118: $1250-77$

Stauffer DR, Seaman NL (1994) On multi-scale four-dimensionl data assimilation. J Appl Meteorol 33: 416-34

Sundqvist H (1978) A parameterization scheme for nonconvective condensation including prediction of cloud water content. Quart J Roy Meteorol Soc 104: 677-90

Tiedtke M (1989) A comprehensive mass flux scheme for cumulus parameterization in large-scale models. Mon Wea Rev 117: 1779-1800

Tiedtke M (1993) Representation of clouds in large-scale models. Mon Wea Rev 121: 3040-61

Troen I, Mahrt L (1986) A simple model of the atmospheric boundary layer: sensitivity to surface evaporation. Bound Layer Meteorol 37: 129-48

Uccellini LW, Kocin PJ (1987) The interaction of jet streak circulations during heavy snow events along the east coast of the united states. Wea Forecast 2: 289-308

Uccelini LW, Kocin PJ, Schneider RS, Stokols PM, Dorr RA (1995) Forecasting the 12-14 March 1993 superstorm. Bull Am Meteorol Soc 76: 183-99

Viterbo P, Beljaars ACM (1995) An improved land surface parameterization scheme in the ECMWF model and its validation. J Climate 8(11): 2716-48

Walcek CJ (1994) Cloud cover and its relationship to relative humidity during a springtime midlatitude cyclone. Mon Wea Rev 122: 1021-35

Williamson D, Boyle J, Cederwall R, Fiorino M, Hnilo J, Olson J, Phillips T, Potter G, Xie S (2005) Moisture and temperature balances at the atmospheric radiation measurement southern great plains site in forecasts with the community atmosphere model 2 (CAM2). J Geophys Res 110: D15S16; DOI: 10.1029/2004JD005109

Williamson DL, Rasch PJ (1989) Two-dimensional semiLagrangian transport with shape preserving interpolation. Mon Wea Rev 117: 102-29

Williamson DL, Rasch PJ (1994) Water vapour transport in the NCAR CCM2. Tellus 46A: 34-51

Xu KM, Kruger SK (1991) Evaluation of cloudiness parameterizations using a cumulus ensemble model. Mon Wea Rev 119: 342-67 